This is the final peer-reviewed accepted manuscript of:

Genetic parameters of muscle fatty acid profile in a purebred Large White heavy pig population Zappaterra M.; Catillo G.; Belmonte A. M.; Lo Fiego D. P.; Zambonelli P.; Steri R.; Buttazzoni L.; Davoli R.

Meat Science, 163, May 2020, 108057

The final published version is available online at: https://doi.org/10.1016/j.meatsci.2020.108057

Rights / License:

The terms and conditions for the reuse of this version of the manuscript are specified in the publishing policy. For all terms of use and more information see the publisher's website.

This item was downloaded from IRIS Università di Bologna (https://cris.unibo.it/)

When citing, please refer to the published version. 


\section{Genetic parameters of muscle fatty acid profile in a purebred Large}

\section{White heavy pig population}

Zappaterra Martina $^{\mathrm{a} *}$, Catillo Gennaro ${ }^{\mathrm{b}}$, Belmonte Anna Maria ${ }^{\mathrm{c}}$, Lo Fiego Domenico Pietro $^{\mathrm{c}, \mathrm{d}}$, Zambonelli Paolo ${ }^{\mathrm{a}}$, Steri Roberto ${ }^{\mathrm{b}}$, Buttazzoni Luca ${ }^{\mathrm{b}}$, Davoli Roberta ${ }^{\mathrm{a}}$

${ }^{a}$ Department of Agricultural and Food Sciences (DISTAL), University of Bologna, Viale G. Fanin 46, I-40127, Bologna, Italy.

${ }^{\mathrm{b}}$ Consiglio per la ricerca in agricoltura e l'analisi dell'economia agraria (CREA) - Centro di ricerca Zootecnia e Acquacoltura (Research Centre for Animal Production and Aquaculture), Via Salaria 31, I-00015, Monterotondo, Italy.

${ }^{c}$ Department of Life Sciences, University of Modena and Reggio Emilia, Via G. Amendola 2, I42122, Reggio Emilia, Italy.

${ }^{\mathrm{d}}$ Interdepartmental Research Centre for Agri-Food Biological Resources Improvement and Valorization (BIOGEST-SITEIA), University of Modena and Reggio Emilia, P. le Europa 1, I42124, Reggio Emilia, Italy.

*These authors contributed equally to this work.

Corresponding author: Roberta Davoli, e-mail: roberta.davoli@unibo.it 
Declarations of interest: Roberta Davoli declares to be a member of Meat Science journal Editorial board. The other co-authors declare that they have no competing interests.

Martina Zappaterra: martina.zappaterra2@unibo.it

Gennaro Catillo: gennaro.catillo@crea.gov.it

Anna Maria Belmonte: annamaria.belmonte@unimore.it

Domenico Pietro Lo Fiego: domenicopietro.lofiego@unimore.it

Paolo Zambonelli: paolo.zambonelli@unibo.it

Roberto Steri: roberto.steri@crea.gov.it

Luca Buttazzoni: luca.buttazzoni@crea.gov.it

Roberta Davoli: roberta.davoli@unibo.it

\begin{abstract}
Semimembranosus muscle samples from 795 Large White heavy pigs were used to determine their intramuscular fatty acid composition and to estimate the heritability and the genetic correlations of these traits. Muscle fatty acids showed heritability estimates of low-to-moderate magnitude, ranging from 0.157 for total fatty acids to 0.237 for docosahexaenoic acid. Only small differences in heritability appeared among fatty acids based on their chain length, saturation and double bond position. Omega-6 polyunsaturated fatty acids showed positive genetic correlations with carcass lean $\%(0.563 \pm 0.005)$ and loin thickness $(0.438 \pm 0.005)$ while being negatively related to backfat thickness measured both by calibre $(-0.225 \pm 0.008)$ and Fat-O-Meat'er $(F O M)$ apparatus $(-0.603 \pm$ 0.004). Interestingly, the monounsaturated fatty acid class was not correlated with carcass measures
\end{abstract}


and presented only a weak positive genetic correlation with intramuscular fat $(0.145 \pm 0.002)$. This result suggests that in heavy pig breeds monounsaturated fatty acids in muscle could be selected for without interfering with carcass traits.

Keywords: heritability; genetic correlation; Semimembranosus muscle; pork; meat quality; fat.

\section{Introduction}

Over the last decades, the swine industry has mainly prioritised production efficiency and increased lean mass growth, with a consistent decrease in the fat depots stored in carcass and muscle (Wood et al., 2008). In this scenario, the heavy pig industry has shaped distinct selection goals in Mediterranean countries such as Spain and Italy to develop selection schemes more suitable for the production of high-value seasoned meat products, such as high-quality dry-cured hams and salamis. The breeding objectives in these countries combine carcass conformation traits (ham and loin weights and conformations) with the maintenance of suitable amounts of subcutaneous and intramuscular fat (Silió, 2000; Bosi \& Russo, 2004). Indeed, fat thickness strongly affects dry-cured ham quality, since an appropriate fat layer prevents hams from excessive seasoning losses and the worsening of organoleptic characteristics (Bosi \& Russo, 2004). In addition to fat thickness, seasoning losses in dry-cured hams also depend on the amount of fat stored in muscles, since the presence of more intermuscular and intramuscular fat were proven to increase the seasoning yields (Bosi \& Russo, 2004). The amount and composition of intramuscular fat are important factors determining meat quality and therefore consumers' acceptance (Wood et al., 2008). Even though an increase in the degree of lipid unsaturation in meat could be beneficial for human health (Caggiula \& Mustad, 1997; Kritchevsky, 1998; Simopoulos, 2008), unsaturated (and in particular polyunsaturated) fatty acids (FA) are more likely to incur in oxidative phenomena, especially in 
seasoned products such as Parma ham (Lo Fiego, Santoro, Macchioni, \& De Leonibus, 2005). Therefore, the seasoning industry technological requirements and the consumers' dietary demands do not completely match. These contrasting demands raise the necessity to elucidate the factors underlying meat traits and qualitative characteristics, in order to find a balance between what is important for the consumer and what for the industry. So far, efforts have been made to improve pork meat quality and an extensive body of literature focuses on aspects affecting the qualitative characteristics and FA composition of the final meat products (Wood et al., 2008; Kim et al., 2018). The relevance of pig diet in modulating muscle and carcass fat deposition and composition has been extensively reported in literature (Lo Fiego, Macchioni, Santoro, Pastorelli, \& Corino, 2005; Minelli, Macchioni, Ielo, Santoro, \& Lo Fiego, 2013; Jasińska \& Kurek, 2017; Minelli et al., 2019), but also breed and genetics affect the animal adipogenic potential (Wood et al., 2004; Wood et al., 2008). Several authors have determined the heritability of intramuscular fat deposition and composition in pigs, showing heritability values $\left(\mathrm{h}^{2}\right)$ ranking from 0.15 to 0.55 (Ntawubizi et al., 2010; Ibáñez-Escriche, Magallón, Gonzalez, Tejeda, \& Noguera, 2016). The high $\mathrm{h}^{2}$ estimates reported by these authors strongly support a direct role for genetics in influencing the intramuscular fat composition. However, these estimates may vary considerably among pig populations and breeds, as reported by Zhang et al. (2018). The lack of agreement among different studies may also depend on the statistical methods used, on the type of information used to calculate genetic parameters (whether the authors have genomic data or only pedigree-based information; Song, Zhang, Zhang, \& Ding, 2019) and/or the phenotypic and genetic features of the studied population. The latter point is also strongly dependent on the structure of the population and on the distinct breeding goals pursued across countries since these differences can affect the estimation of the genetic parameters (Robertson, 1977). In this scenario, the peculiar selection objectives of Italian pig breeding programs have shaped the genetics of the purebred pigs reared for the production of heavy carcasses. In our previous study (Davoli et al., 2019) we investigated the genetic parameters of the backfat FA profile in the Italian Large White pig population and, to the best of our 
knowledge, no study exists giving estimates of the genetic parameters of muscle FA composition in this breed. Subcutaneous and intramuscular fat (IMF) show specific development and metabolism (Mourot, Kouba \& Peiniau, 1995) and several studies have reported considerable anatomical variation in FA composition in the pig adipose tissues (Ros-Freixedes, Reixach, Bosch, Tor \& Estany, 2014; Popova, Nakev \& Marchev, 2015; Jiang et al., 2018). The aim of the present research is to estimate the heritability and genetic correlations of the Semimembranosus muscle (SM) IMF FA composition in a sample of Sib tested Italian Large White pigs bred for heavy pig production. The pedigree-based heritability values obtained for muscle FA composition were furthermore compared with the estimates based on genomic data available from a previous study for the same pig population, in order to compare the reliability of the heritability values estimated using the two approaches.

\section{Material and methods}

\subsection{Animals and phenotypes}

This study was carried out on a sample of 795 Italian Large White (ILW) pigs belonging to the population described by Davoli et al. (2019). Briefly, the pigs were from the national sib testing selection program of the Italian National Association of Pig Breeders (Associazione Nazionale Allevatori Suini, ANAS, http://www.anas.it). During the testing period, siblings were kept separated, fed the same finishing diet at a quasi ad libitum feeding level until an average final live weight of about $150 \mathrm{~kg}$. Pigs were slaughtered in 27 different days between 2011 and 2012 at the same commercial abattoir. During Sib-Test, each litter made by three full-sibs females and castrated males was slaughtered in at least two different dates. The animals used in this study belonged to 324 litters: 48 litters were made by one pig, 81 litters comprised two full-sibs, and the remaining 195 litters were constituted by three full-sibs. Animal care and slaughter of the animals used in this 
study were performed in compliance with the European rules (Council Regulation (EC) No. 1/2005 and Council Regulation (EC) No. 1 099/2009) on the protection of animals during transport and related operations and at the time of the killing. All slaughter procedures were monitored by the veterinary team appointed by the Italian Ministry of Health. Sampling occurred with the ANAS permission. SM samples were taken on the trimming line from the thigh of the left carcass side, at the same point in all carcasses, and were then wrapped in aluminium foil, immediately put in vacuum-sealed bags and frozen in liquid nitrogen. The samples were kept at $-20^{\circ} \mathrm{C}$ for further use.

At slaughtering, hot carcass weight $(\mathrm{kg})$ and backfat thickness (BFT) measured in mm by a calibre at the level of Gluteus medius muscle were measured. Furthermore, optical measures (in mm) of loin and backfat were taken by Fat-O-Meat'er (FOM - CrometecGmbh, Lünen, Germany) between the third and fourth last ribs, $8 \mathrm{~cm}$ off the carcass midline were recorded, together with the estimated percentage of lean meat. The high carcass weight $(118.61 \pm 8.66 \mathrm{~kg})$ of the animals considered in the present study approaches the weight of typical heavy pigs grown for the production of heavy carcasses and high quality dry-cured hams, such as Parma and San Daniele, in compliance with official guidelines for the production of Parma and San Daniele hams (Commission Regulation (EC) No 1 107/96 of 12 June, 1996).

The SM content of IMF was determined by extraction with petroleum ether from $1 \mathrm{~g}$ of fresh tissue by means of an XT15 Ankom apparatus (Macedon, NY, USA), according to Official procedure AOCS Am 5-04 (AOAC, 2005). IMF was reported as g of IMF per $100 \mathrm{~g}$ of tissue (\%).

\subsection{Genotyping and quality control}

The DNA of 795 ILW pigs was genotyped using the PorcineSNP60 v2 BeadChip (Illumina Inc., San Diego, CA, USA), which contains 61,565 SNP markers across the whole genome. 
Quality control of the genomic data was performed using PLINK (Purcell et al., 2007), and the markers that did not satisfy the following criteria were excluded: call rate for SNP $>95 \%$, minor allele frequency $(\mathrm{MAF}) \geq 0.01$ and Hardy-Weinberg equilibrium with $P$-value $\geq 0.001$. The call rate was also computed and individuals with more than $10 \%$ of missing data were removed. After quality control, 783 pigs and 40,115 SNPs were retained.

\subsection{Lipids extraction and Gas-Chromatographic analysis}

The total IMF destined to the gas-chromatographic analysis were extracted from SM by chloroform:methanol mixture (2:1, v/v) (Carlo Erba Reagents, MI, Italy) according to the method of Folch, Lees, \& Sloane Stanley (1957).

The extracted lipids were submitted to methylation before the gas-chromatographic (GC) analysis. Two mL of Hexane (for UV, IR, HPLC, ACS Reag. Ph. Eur., Carlo Erba reagents, MI, Italy) and $200 \mu \mathrm{L}$ of methanolic solution of $2 \mathrm{~N}$-potassium hydroxide (Carlo Erba reagents, MI, Italy) were added to $25 \mathrm{mg}$ of sample. As an internal standard, tridecanoic acid (Larodan AB, Solna, Sweden) was used according to Ficarra et al. (2010). The fatty acid methyl esters (FAMEs) were analyzed using TRACE ${ }^{\mathrm{TM}}$ GC Ultra (Thermo Electron Corporation, Rodano, MI, Italy) equipped with a Flame Ionization Detector, a PVT injector, and a TR-FAME Column 30m x 0.25 mm i.d., $0.2 \mu \mathrm{m}$ film thickness (Thermo Scientific, Rodano, MI, Italy). Helium was used as a carrier gas and it had a flow rate of $1 \mathrm{~mL} / \mathrm{min}$. The injection of FAME sample $(1 \mu \mathrm{L})$ was performed in split mode with a split flow of $10 \mathrm{~mL} / \mathrm{min}$, and operating in a constant condition of carrier gas. Injector and detector were kept at $240^{\circ} \mathrm{C}$ and the initial oven temperature was $140^{\circ} \mathrm{C}$. After the first two minutes, the temperature increased by $4^{\circ} \mathrm{C} / \mathrm{min}$ to reach the final temperature of $250^{\circ} \mathrm{C}$, and this was kept for 5 min. The Chrom-Card software (vers.2.3.3, Thermo Electron Corporation, Rodano, MI, Italy) was used to record and integrate the peaks of FAMEs. Each FA was identified by comparing the 
obtained retention times with the retention times of standard solutions with known quantities of each methyl esters (Larodan AB, Solna, Sweden). The response factor was calculated and the method of internal standard was used for quantification purposes. The FA and FA classes were expressed as mg/g of IMF and the complete list of FA is reported in Supplementary Table S1.

\subsection{Statistical analysis}

Experimental data included information on a three-generation pedigree, with animals showing an average inbreeding coefficient of $4.38 \%$, as reported in Davoli et al. (2019). Given its low level, inbreeding was not considered in the model any further. The influence of the level of fattening of the carcass on the acidic composition of the intramuscular fat was evaluated both for each single FA and for the classes of FA (Saturated FA-SFA, monounsaturated FA- MUFA, polyunsaturated FAPUFA, $n-3$ and $n-6$ PUFA).

Data were analysed with the procedure PROC GLM of the SAS 9.4 software by linear models as described below:

Model 1: $y=M+S L A U+S E X+C L A S S+A G E+$ litter + error where $y$ is the observation vector for the ith trait; SLAU is the slaughter day (27 levels); SEX: two levels for barrows and gilts; CLASS is the thickness of the backfat measured with calibre: 4 levels (see below for a detailed description); $A G E$ at slaughtering (covariate: 1 level); litter has been modeled as random factor (324 levels); error represents random effects of residues.

The four classes of subcutaneous fat thickness were defined based on the quartile values estimated with the UNIVARIATE procedure of the SAS software. It turned out that this character follows a normal distribution and the Shapiro-Wilk test has a $P$-value of 0.0002 . The distribution was divided into quartiles: the first has a value of $23 \mathrm{~mm}$ and it includes the $25 \%$ leaner carcasses; the second 
$(26 \mathrm{~mm})$ corresponds to the median and it includes one-half of carcasses, the third quartile $(30 \mathrm{~mm})$ the $75 \%$ of carcasses. The four classes were defined accordingly: the first includes all the values less than $23 \mathrm{~mm}(\mathrm{n}=163)$; the second from 23 to $26(\mathrm{n}=213)$; the third from 27 to $30(\mathrm{n}=214)$; the fourth all values greater than $30 \mathrm{~mm}(\mathrm{n}=175)$.

The same data set was used to estimate genetic parameters, such as variance components, heritability and the genetic correlations among FA components. Estimates were calculated by restricted maximum likelihood methodology using the VCE software system version 6 (Groeneveld, Kovač, \& Mielenz, 2010) and were carried out by two multiple trait animal models: one involving the measures recorded at slaughtering added with individual FA, the other involving the same measurements at slaughtering added with FA classes. The multiple trait animal models are mixed infinitesimal models where all the individual FA or FA classes were fitted together. The used models are the following:

Model 2: $y=M+S L A U+S E X+A G E+$ litter + animal + error

where $y$ is the observation vector for the ith trait; SLAU is the fixed factor of the slaughter day (27 levels); $S E X$ is the fixed factor of sex with two levels for barrows and gilts; $A G E$ at slaughtering is the covariate effect (1 level); litter has been modeled as random factor (324 levels); animal includes the random additive genetic effect of the animals with and without records (795 level); error represents random effects of residues.

The estimate of genomic heritability was performed with GenABEL package in R environment (Aulchenko, Ripke, Isaacs, \& van Duijn, 2007) using a univariate model with a genomic kinship matrix instead of the classical pedigree-based kinship matrix. The model was fitted using as fixed effects the slaughter day (27 levels), the sex (2 levels), the litter (324 levels) and the covariate on age at slaughtering. 


\section{Results and Discussion}

\subsection{Semimembranosus muscle fatty acid composition in Italian Large White heavy pigs}

Descriptive statistics for the recorded phenotypes are reported in Table 1. The most abundant FA are oleic (C18:1 cis-9), palmitic (C16:0), stearic (C18:0) and linoleic (C18:2 cis-9, cis-12) acids. The amounts observed in our sample for these FA are in agreement with the values reported in previous researches on pigs slaughtered at an average live weight of $145 \mathrm{~kg}$ (Lo Fiego, Macchioni, Minelli, \& Santoro, 2010), where oleic, palmitic, stearic and linoleic acids accounted in Longissimus lumborum muscle for about $42.2 \%, 23.7 \%, 12.4 \%$ and $11.2 \%$ of the total IMF FA, respectively. The $n-6 / n-3$ ratio noticed in the studied pig population was higher than reported by Minelli et al. (2019) for immunocastrated medium-heavy pigs slaughtered at about $142 \mathrm{~kg}$ live weight (22.9 in the present study vs. 15.9 in Minelli et al., 2019). These differences may be ascribed to the different muscles considered (SM in the present study vs. Longissimus lumborum in Minelli et al., 2019), to the different genetic types used (pure breed $v s$. crossbreed) and/or to immunocastration, which may affect the $n-6 / n-3$ ratio (Grela, Kowalczuk-Vasilev \& Klebaniuk, 2013). Similarly, the $n-6 / n-3$ ratios described by Corino, Musella, \& Mourot (2008) and Enser, Richardson, Wood, Gill, \& Sheard (2000) were consistently lower (12.2 and 8.8, respectively) than the value reported in the present research. These differences, however, may also depend on the different slaughter weight of the considered animals. Indeed, while the pigs investigated in Corino, Musella, \& Mourot (2008) and Enser, Richardson, Wood, Gill, \& Sheard (2000) were slaughtered at about $110 \mathrm{~kg}$ and $98 \mathrm{~kg}$ live weight, respectively, the ILW pigs considered for the present study were slaughtered at higher weights. For Parma and San Daniele ham productions, high values of PUFA, and in particular $n$-3 PUFA, are undesirable because they increase ham oxidability (Bosi \& Russo, 2004). On the contrary, SFA and MUFA are less likely to incur in oxidative and lipolytic processes and thus are better regarded as desirable FA by the ham processing industry. In this trial 
MUFA and SFA represented the main FA classes noticed in SM, accounting for $313.71 \pm 68.02$ and $239.66 \pm 44.77$ respectively.

FA composition in muscle showed to depend on sex and overall carcass fatness (Table 2).

According to literature, sex of animals is an important source of variation, influencing the majority of the FA amounts in meat (Juárez et al., 2017). As compared to gilts, barrows showed higher contents in IMF and significantly higher contents of several SFA and MUFA, namely palmitic, stearic, oleic, vaccenic (C18:1 cis-11), arachidic (C20:0) and gadoleic (C20:1 cis-11) acids. On the contrary, gilts showed higher contents of PUFA in the SM, thus exhibiting greater amounts of $n-6$ and n-3 PUFA, linoleic, $\alpha$-linolenic (C18:3n-3), eicosadienoic (C20:2n-6), arachidonic (C20:4 n6), docosapentaenoic (C22:5n-3) and docosahexaenoic (C22:6n-3) FA. In this trial, the estimated effect of sex on IMF content and FA composition is in agreement with previous results, where castrated males had higher total fat content and increased amounts of some FA compared to gilts (Barton-Gade, 1987; Bertol et al., 2013; Juárez et al., 2011; Lo Fiego, Macchioni, Minelli, \& Santoro, 2010; Minelli, Macchioni, Ielo, Santoro, \& Lo Fiego, 2013; Stupka et al., 2008). These results are also consistent with the direct proportionality expected between the amount of fat stored and the proportion of PUFA (Wood et al., 2008). Therefore, the lower SFA content observed in gilt muscle could be explained by the lower IMF deposition in their SM $(1.91 \pm 0.08 \%$ in gilts $v s .2 .09$ $\pm 0.09 \%$ in barrows). Beyond different adipogenic potentials, sex seems to be related also to a distinct deposition of some specific FA, as reported by Geri, Franci, Poli, Campodoni, \& Zappa (1990) and Juárez et al. (2017). In agreement with our results, previous studies showed that, compared to barrows, gilts tends to store more PUFA and linoleic acid, and less oleic and SFA, in subcutaneous fat (Geri, Franci, Poli, Campodoni, \& Zappa, 1990; Lo Fiego, Macchioni, Minelli, \& Santoro, 2010) and muscle (Juárez et al., 2017; Lo Fiego, Macchioni, Minelli, \& Santoro, 2010). This difference could find a functional explanation insofar PUFA are more readily available for supporting reproductive and nursing purposes (Raclot \& Groscolas, 1994). 
Together with sex, also the grade of carcass fatness showed to affect SM fat deposition and composition. Considering the four quartile categories obtained for backfat thickness and reported in Table 2, it is possible to observe that backfat thickness is associated with both IMF and the level of several muscle FA. The animals belonging to the first backfat thickness class (less than $23 \mathrm{~mm}$ ) showed the lowest \% of IMF (1.84\%), significantly different from the IMF in the thickest group, the fourth $(2.153 \%)$. This result is in agreement with previous studies (Wood, Enser, Whittington, Moncrieff, \& Kempster, 1989) and with the commonly accepted view that IMF and subcutaneous fat share, at least in part, a common genetic basis, as reviewed in Pena, Ros-Freixedes, Tor, \& Estany (2016) and reported in our previous study (Davoli et al., 2019). Together with IMF, a thicker backfat layer is also associated with increased contents of SFA in SM, namely capric (C10:0), myristic (C14:0), palmitic and oleic acids. Together with them, also palmitoleic (C16:1 cis-9) and vaccenic acids had higher contents in the muscle of pigs with high adipogenic potential.

An opposite trend was observed for most of the $n-6$ and n-3 FA and for PUFA, $n-6$ PUFA, and $n-3$ PUFA classes, which showed higher contents in the muscle of pigs with a thinner backfat layer. The only exceptions were the SFA heptadecenoic acid (C17:0), showing greater amounts in leaner pigs, and eicosapentaenoic acid (C20:5 n-3), which, despite being an $n$-3 PUFA, was higher in animals with high subcutaneous fat thickness. The essential FA, namely linoleic (C18:2 cis-9, cis-12) and $\alpha-$ linolenic (C18:3n-3) acids were higher in animals with lower fat deposition. This trend is in agreement with the results in the literature showing that lower amounts of stored fat are associated with higher proportions of PUFA (Matthews, 2011). UFA are essential components of cell membranes, and while the storage of energy through SFA may change among individuals and over time, in individuals fed the same diet the amount of UFA remains stable due to their important roles in membrane flexibility, inflammation control, eicosanoid production, plasma triacylglycerol synthesis and gene expression (reviewed in Fernandez \& West, 2005). Furthermore the observed negative relation occurring between PUFA and backfat thickness may also be related to the role of 
several PUFA (in particular $n$-3 PUFA) in influencing blood-circulating Low Density Lipoprotein (LDL) level, fat deposition and fat-related chronic inflammation processes (reviewed in Fernandez \& West, 2005; Wang \& Huang, 2015).

\subsection{Heritability estimates for Semimembranosus muscle fatty acid composition}

Estimated variance components and heritability values of individual FA and FA classes are reported in Table 3 and Table 4, respectively. On the whole, the heritability values estimated for muscle FA were moderate, ranging from $0.177 \pm 0.004$ to $0.237 \pm 0.001$ for capric and docosahexaenoic acid (DHA; C22:6n-3), respectively. Similarly, FA classes showed heritability estimates of low-tomoderate magnitude, varying little from $0.209 \pm 0.002$ for $n$ - 6 PUFA to $0.226 \pm 0.001$ for PUFA.

Only small differences in heritability appeared among FA based on their chain length, saturation and double bond position. The linoleic and $\alpha$-linolenic essential FA showed a moderate level of heritability $(0.219 \pm 0.001$ and $0.223 \pm 0.001$, respectively), suggesting partial genetic control of digestion, absorption and utilisation mechanisms regulating their storage in muscle. Interestingly, also $n-6 / n-3$ ratio resulted to be moderately heritable $\left(h^{2}=0.228\right)$. Despite this trait being largely affected by feeding factors (De Smet, Raes, \& Demeyer, 2004), the heritability found for the $n-6 / n$ 3 ratio suggests a genetic basis for its variability does exist. The heritabilities observed in the present work are on the whole less variable and lower than those reported in the literature for the IMF content and for muscle FA composition (Sellier, Maignel, \& Bidanel, 2010; Ibáñez-Escriche, Magallón, Gonzalez, Tejeda, \& Noguera, 2016; Zhang et al., 2016). These differences may be caused by the different statistical models used to estimate the heritabilities in the studies in literature, and by the phenotypic and genetic features of the studied population (Robertson, 1977; Zhang et al., 2018). Indeed, the structure of the populations and the different breeding goals pursued across countries may have affected the differences observed among the results of this work and the 
literature. The Italian pig breeding system has shaped the genetics of its purebred pigs reared for the production of heavy carcasses, differentiating these animals from those selected for fresh meat production. Pedigree-based heritability values were on the whole consistent with genomic $\mathrm{h}^{2}$ coefficients obtained integrating molecular marker information (Supplementary Table S2), as shown in Figure 1. Genomic heritability estimates showed greater variability between the different FA than pedigree-based $h^{2}$ coefficients, possibly because the first were estimates from univariate analyses and the latter from multivariate analysis. However, the average values from the two types of estimates were on the whole similar ( 0.237 and 0.222 for genomic and pedigree-based coefficients, respectively). Genomic and pedigree heritabilities were most different for palmitoleic, heptadecenoic (C17:1 cis-9), vaccenic, $\gamma$-linolenic acid (C18:3n-6), eicosatrienoic (C20:3n-3), docosahexaenoic, and, to a less extent, for eicosapentaenoic acid. In particular, palmitoleic, vaccenic, eicosatrienoic and docosahexaenoic acids showed higher genomic heritability values than the corresponding pedigree-based $\mathrm{h}^{2}$ coefficients. The higher genomic heritability can be explained either by a greater genetic control over these traits or by an overestimation of the genetic variance due to the presence of an imperfect linkage disequilibrium existing between the DNA markers and the Quantitative Trait Loci (QTLs) controlling the traits (de los Campos, Sorensen \& Gianola, 2015).

\subsection{Genetic correlations between Semimembranosus muscle fatty acid}

\section{composition and carcass traits}

Examining the genetic correlations occurring between FA and carcass traits it is possible to identify some recursive correlation patterns. In Table 5 only a few significant correlations (heptadecenoic and linoleic acids) are reported between single FA and hot carcass weight, suggesting that in our samples the SM FA content is not related to the weight of the animals. The same behaviour can be 
observed also for the correlations between single FA and BFT measured by calibre. Only three FA are genetically correlated with subcutaneous fat depots: in particular, capric acid shows a weak positive correlation while heptadecenoic and linoleic acids are negatively correlated with BFT. Considering now the measures obtained by the FOM apparatus, we can observe that the majority of analysed FA is related to those measures. Indeed, several MUFA and PUFA are positively associated with lean \% and loin thickness while being negatively correlated with BFT measured by FOM. A significant negative correlation between lean meat content and the content of some FA, namely capric and palmitoleic acids, was also found. The correlation between FA and IMF is positive and highly significant for C10 to C20 SFA and for the MUFA oleic, vaccenic and C20:1 cis-11. These results are in agreement with the fact that triacylglycerols, the main neutral lipids used to store energy in muscle, mainly consists of SFA and MUFA (De Smet, Raes, \& Demeyer, 2004). On the contrary, the correlation is negative and highly significant for many PUFA. From Table 6, it is possible to note that the FA classes of PUFA, $n$-6 PUFA, and $n$-3 PUFA were positively correlated with measures related to lean mass deposition (hot carcass weight, lean \% and loin thickness) and negatively related to BFT measured with the calibre and FOM, in agreement with the general view that PUFA amounts on total FA are negatively related to fat depository (De Smet, Raes, \& Demeyer, 2004; Matthews, 2011). Interestingly, the MUFA class did not show to be correlated with carcass measures and presented only a weak positive correlation with IMF $(0.145 \pm$ 0.002). This result is in agreement with the evidence reported in Davoli et al. (2019) for the amount of MUFA in backfat. Indeed, also in that previous work, hardly any genetic correlation was observed both for BFT and loin thickness with MUFA (Davoli et al., 2019), suggesting that in heavy pig breeds MUFA could be selected for with no direct effects on carcass traits. This result could be relevant considering that a growing number of studies have pointed out the importance of dietary MUFA for consumers' health. Indeed MUFA such as C16 positional isomers and oleic acid, seem to display desirable effects (Terés et al., 2008; Calder, 2015), while they have hardly any impact on the organoleptic quality of seasoned pork products. However, further studies are 
necessary to elucidate the possible direct response of selection for MUFA on PUFA and SFA and the correlated combined effects of the last two classes on carcass characteristics.

\subsection{Genetic correlations among Semimembranosus muscle fatty acids}

The genetic correlations between muscle FA classes and the relative standard errors are reported in Table 7. In this study, all genetic correlations among FA classes showed to be positive, except for the muscle $n-6 / n-3$ ratio, which showed negative correlations with all of the other FA categories and with muscle total lipids. The positive correlations found between SFA, MUFA and PUFA and the apparent discrepancy with other results reported in literature (Ntawubizi et al., 2010) can be explained because the SM FA composition considered in the present research is reported as absolute value (mg/g of IMF) and not as percentage on the total FA.

The complete matrix of estimated genetic correlations among FA is reported in Supplementary Table S3. The highest genetic correlations were between the essential FA linoleic and $\alpha$-linolenic acids with the other muscle FA. Linoleic and $\alpha$-linolenic acids were positively correlated with eicosadienoic acid (C20:2 n-6), eicosatrienoic acid and docosapentaenoic acid (C20:5 n-3). Essential FA play an important functional role in monogastric mammals since they need to be supplied by the diet. Indeed, monogastric mammals are not able to synthesize the enzymes responsible for introducing double bonds beyond carbons 9 and 10 (Sprecher, Luthria, Mohammed, \& Baykousheva, 1995), therefore they are not able to synthesize de novo significant amounts of essential FA. Anyway, monogastric mammals can successfully elongate and desaturate linoleic and $\alpha$-linolenic acids into longer chain PUFA (Brenner, 1974). This biosynthetic pathway linking essential FA with longer chain PUFA, such as eicosadienoic, eicosatrienoic and docosapentaenoic acids, may explain the positive genetic correlations noticed among these FA. Furthermore, high positive correlations were also found among SFA with a number of carbon atoms comprised 
between 10 and 16. This result may be associated with the fact that these medium-chain FA are mainly de novo synthesized through subsequent elongation steps by the Fatty acid synthase (FASN) enzyme. FASN has a complex homodimeric structure with the major role of regulating the de novo synthesis of long-chain FA in mammals through the formation of 16-carbon FA from acetyl-CoA and malonyl-CoA (Chakravarty, Gu, Chirala, Wakil, \& Quiocho, 2004). This synthesis involves a cyclic-step elongation of the precursors by 2 carbon units (Smith, 1994) and the growing FA is generally released when the chain reaches 16 carbon atoms in length.

\section{Conclusions}

On the whole, SM FA composition showed to be a moderately heritable trait and thus it could be directly modified through genetic selection. Interestingly, genomic and pedigree-based heritabilities estimated for muscle FA were on the whole similar. Palmitoleic, vaccenic, eicosatrienoic and docosahexaenoic acids showed higher genomic heritabilities compared with the corresponding pedigree-based $\mathrm{h}^{2}$ coefficients. This evidence may suggest that these FA are under greater genetic control than others or, alternatively, the presence of DNA markers in imperfect linkage disequilibrium with the QTLs controlling these FA. Finally, while muscle contents of PUFA were highly correlated with carcass traits, MUFA amounts showed low (or null) genetic correlations with lean and subcutaneous fat measures. In agreement with our previous work on the backfat FA composition, this result seems to indicate that MUFA could be selected for without interfering with carcass traits. However, this hypothesis would require further verification.

\section{Acknowledgements}


The authors thank Dr. Maurizio Gallo from ANAS for providing the muscle samples and the data concerning the studied animals. The authors acknowledge also Andrea Serra and Marcello Mele from the Pisa University for assessing the IMF amount of SM samples.

Funding: This work was supported by PRIN 2015 national project (Grant N. 201549TZXB001) and by AGER - Hepiget project (Grant N. 2011- 0279).

\section{References}

AOAC (2005). Official Methods of Analysis, Method 920.39, Fat (crude) or ether extract in animal feed. 18th edition. Assoc. Anal. Chem., Gaithersburg, MD, USA.

Aulchenko, Y.S., Ripke, S., Isaacs, A., \& van Duijn, C.M. (2007). GenABEL: an R library for genome-wide association analysis. Bioinformatics, 23(10), 1294-1296.

Barton-Gade, P.A. (1987). Meat and fat quality in boars, castrates and gilts. Livestock Production Science, 16(2), 187-196.

Bertol, T.M., de Campos, R.M.L., Ludke, J.V., Terra, N.N., de Figueiredo, E.A.P., Coldebella, A., ... Lehr, N.M. (2013). Effects of genotype and dietary oil supplementation on performance, carcass traits, pork quality and fatty acid composition of backfat and intramuscular fat. Meat Science, 93(3), 507-516.

Bosi, P., \& Russo, V. (2004). The production of the heavy pig for high quality processed products. Italian Journal of Animal Science, 3(4), 309-321.

Brenner, R.R. (1974). The oxidative desaturation of unsaturated fatty acids in animals. Molecular and Cellular Biochemistry, 3(1), 41-52.

Caggiula, A.W., \& Mustad, V.A. (1997). Effects of dietary fat and fatty acids on coronary artery disease risk and total and lipoprotein cholesterol concentrations: epidemiologic studies. American Journal of Clinical Nutrition, 65(5), 1597S-1610S. 
Calder, P.C. (2015). Functional Roles of Fatty Acids and Their Effects on Human Health. Journal of Parenteral and Enteral Nutrition, 39(1), 18S-32S

Chakravarty, B., Gu, Z., Chirala, S.S., Wakil, S.J., \& Quiocho, F.A. (2004). Human fatty acid synthase: Structure and substrate selectivity of the thioesterase domain. Proceedings of the National Academy of Sciences, 101(44), 15567-15572.

Corino, C., Musella, M., \& Mourot, J. (2008). Influence of extruded linseed on growth, carcass composition, and meat quality of slaughtered pigs at one hundred ten and one hundred sixty kilograms of liveweight. Journal of Animal Science, 86, 1850-1860.

Davoli, R., Catillo, G., Serra, A., Zappaterra, M., Zambonelli, P., Meo Zilio, D., ... Russo, V. (2019). Genetic parameters of backfat fatty acids and carcass traits in Large White pigs. Animal, 13(5), 924-932.

de Los Campos, G., Sorensen, D., \& Gianola, D. (2015). Genomic Heritability: What Is It?. PLoS Genetics, 11, e1005048.

De Smet, S., Raes, K., \& Demeyer, D. (2004). Meat fatty acid composition as affected by fatness and genetic factors: a review. Animal Research, 53, 81-98.

Enser, M., Richardson, R.I., Wood, J.D., Gill, B.P., \& Sheard, P.R. (2000). Feeding linseed to increase the n-3 PUFA of pork: fatty acid composition of muscle, adipose tissue, liver and sausages. Meat Science, 55, 201-212.

Fernandez, M.L., \& West, K.L. (2005). Mechanisms by which dietary fatty acids modulate plasma lipids. The Journal of Nutrition, 135(9), 2075-2078.

Folch, J., Lees, M., \& Sloane Stanley, G.H. (1957). A simple method for the isolation and purification of total lipids from animal tissues. Journal of Biological Chemistry, 226, 497509. 
Geri, G., Franci, O., Poli, B.M., Campodoni, G., \& Zappa, A. (1990). Relationships between adipose tissue characteristics of newborn pigs and subsequent performance: II. Carcass traits at 95 and 145 kilograms live weight. Journal of Animal Science, 68(7), 1929-35.

Grela, E.R., Kowalczuk-Vasilev, E., \& Klebaniuk, R. (2013). Performance, pork quality and fatty acid composition of entire males, surgically castrated or immunocastrated males, and female pigs reared under organic system. Polish Journal of Veterinary Sciences, 16(1), 107-114.

Groeneveld, E., Kovač, M., \& Mielenz, N. (2010). VCE User's Guide and Reference Manual Version 6. Retrieved on 28th January 2014 from https://vce.tzv.fal.de/software/download.

Ibáñez-Escriche, N., Magallón, E., Gonzalez, E., Tejeda, J.F., \& Noguera, J.L. (2016). Genetic parameters and crossbreeding effects of fat deposition and fatty acid profiles in Iberian pig lines. Journal of Animal Science, 94(1), 28-37.

Jasińska, K., \& Kurek, M.A. (2017). The effect of oil plants supplementation in pig diet on quality and nutritive value of pork meat. Animal Science Papers and Reports, 35(2), 137-146.

Jiang, Q., Li, C., Yu, Y., Xing, Y., Xiao, D., Zhang, B. (2018). Comparison of fatty acid profile of three adipose tissues in Ningxiang pigs. Animal Nutrition, 4(3): 256-259.

Juárez, M., Dugan, M.E.R., Aldai, N., Aalhus, J.L., Patience, J.F., Zijlstra, R.T., \& Beaulieu, A.D. (2011). Increasing omega-3 levels through dietary co-extruded flaxseed supplementation negatively affects pork palatability. Food Chemistry, 126, 1716-1723.

Juárez, M., Dugan, M.E.R., López-Campos, Ó., Prieto, N., Uttaro, B., Gariépy, C., \& Aalhus, J.L. (2017). Relative contribution of breed, slaughter weight, sex, and diet to the fatty acid composition of differentiated pork. Canadian Journal of Animal Science, 97, 395-405.

Kim, Y.M., Choi, T.J., Ho Cho, K., Cho, E.S., Lee, J.J., Chung, H.J., ... Jeong, Y.D. (2018). Effects of sex and breed on meat quality and sensory properties in three-way crossbred pigs sired by Duroc or by a synthetic breed based on a Korean native breed. Korean Journal for Food 
Science of Animal Resources, 38(3):544-553.

Kritchevsky, D. (1998). History of Recommendations to the Public about Dietary Fat. The Journal of Nutrition, 128(2), 449S-452S.

Lo Fiego, D. P., Macchioni, P., Santoro, P., Pastorelli, G., \& Corino, C. (2005). Effect of dietary conjugated linoleic acid (CLA) supplementation on CLA isomers content and fatty acid composition of dry-cured Parma ham. Meat Science, 70, 285-291.

Lo Fiego, D. P., Santoro, P., Macchioni, P., \& De Leonibus, E. (2005). Influence of genetic type, live weight at slaughter and carcass fatness on fatty acid composition of subcutaneous adipose tissue of raw ham in the heavy pig. Meat Science, 69, 107-114.

Lo Fiego, D.P., Macchioni, P., Minelli, G., \& Santoro, P. (2010). Lipid composition of covering and intramuscular fat in pigs at different slaughter age. Italian Journal of Animal Science, 9(e39), 200-205.

Matthews, K.R. (2011). Saturated fat reduction in butchered meat. In G. Talbot (Ed.), Reducing saturated fats in food (pp.195-209). Cambridge: Woodhead Publishing Limited.

Mensink, R.P., Zock, P.L., Kester, A.D., \& Katan, M.B. (2003). Effects of dietary fatty acids and carbohydrates on the ratio of serum total to HDL cholesterol and on serum lipids and apolipoproteins: a meta-analysis of 60 controlled trials. The American Journal of Clinical Nutrition, 77, 1146-1155.

Minelli, G., Macchioni, P., Ielo, M.C., Santoro, P., Lo Fiego, D.P. (2013). Effects of dietary level of pantothenic acid and sex on carcass, meat quality traits and fatty acid composition of subcutaneous adipose tissue of thighs of Italian heavy pigs. Italian Journal of Animal Science, 12, 329-336. 
Minelli, G., Macchioni, P., Mezzetti, F., Belmonte, A.M., Volpelli, L.A., Faeti, V., Lo Fiego, D.P. (2019). Characteristics of lipids from immunocastrated medium-heavy pigs fed either a restricted diet or ad libitum. Italian Journal of Food Science, 31, 98-109.

Mourot, J., Kouba, M., Peiniau, P. (1995). Comparative study of in vitro lipogenesis in various adipose tissues in the growing domestic pig (Sus domesticus). Comparative Biochemistry and Physiology, 111B, 379-384.

Nieto, G., \& Ros, G. (2012). Modification of fatty acid composition in meat through diet: effect on lipid peroxidation and relationship to nutritional quality- a review. In A. Catala (Ed.), Lipid Peroxidation (pp.239-258). InTech,

Ntawubizi, M., Colman, E., Janssens, S., Raes, K., Buys, N., \& De Smet, S. (2010). Genetic parameters for intramuscular fatty acid composition and metabolism in pigs. Journal of Animal Science, 88, 1286-1294.

Pena, R.N., Ros-Freixedes, R., Tor, M., \& Estany, J. (2016). Genetic Marker Discovery in Complex Traits: A Field Example on Fat Content and Composition in Pigs. International Journal of Molecular Sciences, 17(12), 2100.

Popova, T., Nakev, J., Marchev, Y. (2015). Fatty acid composition of subcutaneous and intramuscular adipose tissue in East Balkan pigs. Biotechnology in Animal Husbandry, 31(4), 543-550.

Purcell, S., Neale, B., Todd-Brown, K., Thomas, L., Ferreira, M.A., Bender, D., ... Sham, P.C. (2007). PLINK: a tool set for whole-genome association and population-based linkage analyses. American Journal of Human Genetics, 81(3), 559-575.Raclot, T., \& Groscolas, R. (1994). Individual fish-oil n-3 polyunsaturated fatty acid deposition and mobilization rates for adipose tissue of rats in a nutritional steady state. American Journal of Clinical Nutrition, 60(1), 72-78. 
Robertson, A. (1977). The effect of selection on the estimation of genetic parameters. Journal of Animal Breeding and Genetics, 94, 131-135.

Ros-Freixedes, R., Reixach, J., Bosch, L., Tor, M., \& Estany, J. (2014). Genetic correlations of intramuscular fat content and fatty acid composition among muscles and with subcutaneous fat in Duroc pigs. Journal of Animal Science, 92(12), 5417-5425.

Sellier, P., Maignel, L., \& Bidanel, J.P. (2010). Genetic parameters for tissue and fatty acid composition of backfat, perirenal fat and longissimus muscle in Large White and Landrace pigs. Animal, 4(4), 497-504.

Silió, L. (2000). Iberian pig breeding programme. In S. Galal, J. Boyazoglu, \& K. Hammond (Eds.), Developing breeding strategies for lower input animal production environments (pp.511519). Rome: ICAR

Simopoulos, A.P. (2008). The importance of the omega-6/omega-3 fatty acid ratio in cardiovascular disease and other chronic diseases. Experimental Biology and Medicine, 233(6), 674-688.

Smith, S. (1994). The animal fatty acid synthase: one gene, one polypeptide, seven enzymes. FASEB Journal: Official Publication of the Federation of American Societies for Experimental Biology, 8(15), 1248-1259.

Song, H., Zhang, J., Zhang, Q., \& Ding, X. (2019). Using different single-step strategies to improve the efficiency of genomic prediction on body measurement traits in pig. Frontiers in Genetics, 9, 730 .

Sprecher, H., Luthria, D.L., Mohammed, B.S., \& Baykousheva, S.P. (1995). Reevaluation of the pathways for the biosynthesis of polyunsaturated fatty acids. Journal of Lipid Research, 36, 2471-2477. 
Stupka, R., Čítek, J., Šprysl, M., Okrouhlá, M., Kureš, D., \& Líkař, K. (2008). Effect of weight and sex on intramuscular fat amounts in relation to the formation of selected carcass cuts in pigs. Czech Journal of Animal Science, 53(12), 506-514.

Terés, S., Barceló-Coblijn, G., Benet, M., Álvarez, R., Bressani, R., Halver, J.E., \& Escribá, P.V. (2008). Oleic acid content is responsible for the reduction in blood pressure induced by olive oil. Proceedings of the National Academy of Sciences, 105, 13811-13816.

Wang, Y., \& Huang, F. (2015). N-3 Polyunsaturated Fatty Acids and Inflammation in Obesity: Local Effect and Systemic Benefit. BioMed Research International, 2015, 581469.

Wood, J.D., Enser, M., Fisher, A.V., Nute, G.R., Sheard, P.R., Richardson, R.I., ... Whittington, F.M. (2008). Fat deposition, fatty acid composition and meat quality: a review. Meat Science, 78(4), 343-358.

Wood, J.D., Enser, M., Whittington, F.M., Moncrieff, C.B., \& Kempster, A.J. (1989).Backfat composition in pigs: differences between fat thickness groups and sexes. Livestock Production Science, 22, 351-362.

Wood, J.D., Richardson, R.I., Nute, G.R., Fisher, A.V., Campo, M.M., Kasapidou, E., ... Enser, M. (2004). Effects of fatty acids on meat quality: a review. Meat Science, 66(1), 21-32.

Zhang, W., Zhang, J., Cui, L., Ma, J., Chen, C., Ai, H., ... Yang, B. (2016). Genetic architecture of fatty acid composition in the longissimus dorsi muscle revealed by genome-wide association studies on diverse pig populations. Genetics Selection Evolution, 48, 5.

Zhang, Y., Zhang, J., Gong, H., Cui, L., Zhang, W., Ma, J., ... Yang, B. (2018). Genetic correlation of fatty acid composition with growth, carcass, fat deposition and meat quality traits based on GWAS data in six pig populations. Meat Science, 150, 47-55. 
Table 1. Descriptive statistics for the studied traits in Semimembranosus muscle with the number of considered pigs $(\mathrm{N})$, the minimum and maximum values, the mean value and the standard deviation (SD).

\begin{tabular}{|c|c|c|c|c|c|}
\hline Traits & $\mathrm{N}$ & Minimum & Maximum & Mean & $\mathrm{SD}$ \\
\hline Hot carcass weigth $(\mathrm{kg})$ & 715 & 89.000 & 137.000 & 118.613 & 8.658 \\
\hline $\operatorname{BFT}(\mathrm{mm})^{1}$ & 795 & 13.000 & 45.000 & 26.616 & 5.091 \\
\hline Lean $(\%)^{2}$ & 715 & 40.700 & 59.100 & 48.982 & 2.808 \\
\hline $\mathrm{BFT}$ FOM $(\mathrm{mm})^{3}$ & 713 & 13.000 & 47.000 & 27.282 & 5.240 \\
\hline Loin thickness $(\mathrm{mm})^{4}$ & 713 & 26.000 & 80.000 & 63.203 & 6.915 \\
\hline $\operatorname{IMF}(\%)^{5}$ & 784 & 0.590 & 8.640 & 2.054 & 1.107 \\
\hline C10:0 (mg/g IMF) & 795 & 0.209 & 1.698 & 0.834 & 0.212 \\
\hline C12:0 (mg/g IMF) & 795 & 0.201 & 1.340 & 0.670 & 0.181 \\
\hline C14:0 (mg/g IMF) & 795 & 2.718 & 14.120 & 8.786 & 2.046 \\
\hline C16:0 (mg/g IMF) & 795 & 67.900 & 235.531 & 151.291 & 28.953 \\
\hline C16:1 cis-9 (mg/g IMF) & 795 & 4.643 & 36.268 & 18.895 & 4.840 \\
\hline C17:0 (mg/g IMF) & 795 & 0.510 & 1.864 & 0.983 & 0.208 \\
\hline C17:1 cis-9 (mg/g IMF) & 795 & 0.719 & 2.773 & 1.468 & 0.335 \\
\hline C18:0 (mg/g IMF) & 795 & 38.144 & 136.904 & 76.094 & 14.510 \\
\hline C18:1 cis-9 (mg/g IMF) & 795 & 100.206 & 419.702 & 263.630 & 58.830 \\
\hline C18:1 cis-11 (mg/g IMF) & 795 & 11.339 & 44.131 & 25.155 & 4.770 \\
\hline $\mathrm{C} 18: 2$ cis-9, cis-12 (mg/g IMF) & 795 & 35.079 & 128.232 & 68.394 & 12.984 \\
\hline C18:3 n-6 (mg/g IMF) & 795 & 0.093 & 1.410 & 0.708 & 0.195 \\
\hline C18:3 n-3 (mg/g IMF) & 795 & 0.109 & 5.140 & 2.400 & 0.698 \\
\hline C20:0 (mg/g IMF) & 795 & 0.080 & 1.998 & 1.003 & 0.265 \\
\hline C20:1 (mg/g IMF) & 795 & 0.168 & 9.000 & 4.443 & 1.191 \\
\hline
\end{tabular}




\begin{tabular}{|c|c|c|c|c|c|}
\hline C20:2 n-6 (mg/g IMF) & 795 & 1.446 & 5.108 & 2.863 & 0.593 \\
\hline C20:3 n-6 (mg/g IMF) & 759 & 0.630 & 3.846 & 1.455 & 0.397 \\
\hline C20:4 n-6 (mg/g IMF) & 795 & 3.155 & 42.286 & 11.287 & 4.265 \\
\hline C20:3 n-3 (mg/g IMF) & 795 & 0.013 & 1.945 & 0.563 & 0.129 \\
\hline C20:5 n-3 (mg/g IMF) & 795 & 0.003 & 0.258 & 0.080 & 0.025 \\
\hline C22:1 (mg/g IMF) & 759 & 0.006 & 0.581 & 0.123 & 0.049 \\
\hline C22:2 n-6 (mg/g IMF) & 795 & 0.006 & 1.697 & 0.571 & 0.294 \\
\hline C22:4 n-6 (mg/g IMF) & 795 & 0.644 & 4.835 & 1.766 & 0.513 \\
\hline $\mathrm{C} 22: 5 n-3(\mathrm{mg} / \mathrm{g}$ IMF) & 795 & 0.166 & 3.340 & 0.674 & 0.239 \\
\hline C22:6 n-3 (mg/g IMF) & 795 & 0.007 & 1.240 & 0.178 & 0.084 \\
\hline Total lipids (mg/g IMF) & 795 & 315.941 & 918.311 & 644.242 & 112.414 \\
\hline SFA $(\mathrm{mg} / \mathrm{g} \text { IMF })^{6}$ & 795 & 120.820 & 384.152 & 239.661 & 44.766 \\
\hline MUFA (mg/g IMF) ${ }^{7}$ & 795 & 118.789 & 492.681 & 313.708 & 68.018 \\
\hline PUFA (mg/g IMF) ${ }^{8}$ & 795 & 48.354 & 177.158 & 90.872 & 16.279 \\
\hline$n-3$ PUFA (mg/g IMF) ${ }^{9}$ & 795 & 1.356 & 7.304 & 3.894 & 0.904 \\
\hline$n-6$ PUFA $(\mathrm{mg} / \mathrm{g} \mathrm{IMF})^{10}$ & 795 & 46.322 & 170.020 & 86.978 & 15.535 \\
\hline$n-6 / n-3$ ratio & 795 & 12.530 & 53.270 & 22.856 & 3.555 \\
\hline
\end{tabular}

${ }^{1}$ Backfat thickness manually measured with a calibre at the level of Gluteus medius muscle.

${ }^{2}$ Percentage of carcass lean meat content estimated using Fat-O-Meat'er (FOM) instrument.

${ }^{3}$ Backfat thickness (including rind) measured with Fat-O-Meat'er (FOM) instrument on the back between the third and fourth last ribs at $8 \mathrm{~cm}$ off the carcass midline.

${ }^{4}$ Loin thickness measured with Fat-O-Meat'er (FOM) instrument on the back between the third and fourth last ribs at $8 \mathrm{~cm}$ off the carcass midline.

${ }^{5}$ Intramuscular fat content measured in Semimembranosus muscle by means of a XT15 Ankom apparatus according to Official procedure AOCS Am 5-04. 
${ }^{6}$ Saturated fatty acids.

${ }^{7}$ Monounsaturated fatty acids.

${ }^{8}$ Polyunsaturated fatty acids.

${ }^{9}$ Omega-3 polyunsaturated fatty acids.

${ }^{10}$ Omega-6 polyunsaturated fatty acids . 
Table 2. Estimated means and standard deviations (SD) of the Semimembranosus muscle fatty acids for the fixed effects of sex and classes of backfat thickness.

\begin{tabular}{|c|c|c|c|c|c|c|}
\hline \multirow[b]{3}{*}{ Traits $^{1}$} & \multicolumn{2}{|c|}{ Sex } & \multicolumn{4}{|c|}{ Backfat thickness classes } \\
\hline & Barrow & Gilt & 1 & 2 & 3 & 4 \\
\hline & Mean \pm SD & Mean \pm SD & Mean \pm SD & Mean \pm SD & Mean \pm SD & Mean \pm SD \\
\hline $\mathrm{IMF}^{2}$ & $2.090 \pm 0.093^{\mathrm{a}}$ & $1.913 \pm 0.077^{\mathrm{b}}$ & $1.840 \pm 0.114^{\mathrm{b}}$ & $2.011 \pm 0.094^{\mathrm{ab}}$ & $2.002 \pm 0.097^{\mathrm{ab}}$ & $2.153 \pm 0.104^{\mathrm{a}}$ \\
\hline C10:0 & $0.812 \pm 0.018$ & $0.805 \pm 0.015$ & $0.78 \pm 0.022^{b}$ & $0.804 \pm 0.018^{\mathrm{ab}}$ & $0.810 \pm 0.019^{\mathrm{ab}}$ & $0.840 \pm 0.020^{\mathrm{a}}$ \\
\hline C12:0 & $0.646 \pm 0.015$ & $0.654 \pm 0.012$ & $0.646 \pm 0.018$ & $0.663 \pm 0.015$ & $0.641 \pm 0.016$ & $0.650 \pm 0.017$ \\
\hline $\mathrm{C} 14: 0$ & $8.570 \pm 0.171$ & $8.486 \pm 0.142$ & $8.254 \pm 0.211^{\mathrm{b}}$ & $8.573 \pm 0.171^{\mathrm{ab}}$ & $8.503 \pm 0.178^{\mathrm{ab}}$ & $8.780 \pm 0.190^{\mathrm{a}}$ \\
\hline C16:0 & $151.329 \pm 2.410^{\mathrm{a}}$ & $146.810 \pm 1.995^{\mathrm{b}}$ & $144.18 \pm 2.963^{b}$ & $149.892 \pm 2.411^{\mathrm{a}}$ & $148.803 \pm 2.505^{\mathrm{ab}}$ & $153.401 \pm 2.674^{\mathrm{a}}$ \\
\hline C16:1 cis-9 & $18.706 \pm 0.405$ & $18.185 \pm 0.335$ & $17.307 \pm 0.498^{c}$ & $18.331 \pm 0.405^{\mathrm{bc}}$ & $18.698 \pm 0.421^{\mathrm{ab}}$ & $19.445 \pm 0.449^{\mathrm{a}}$ \\
\hline $\mathrm{C} 17: 0$ & $0.966 \pm 0.017$ & $0.978 \pm 0.014$ & $1.025 \pm 0.021^{\mathrm{a}}$ & $0.981 \pm 0.017^{\mathrm{b}}$ & $0.935 \pm 0.018^{\mathrm{c}}$ & $0.946 \pm 0.019^{\mathrm{bc}}$ \\
\hline $\mathrm{C} 17: 1$ cis -9 & $1.446 \pm 0.028$ & $1.441 \pm 0.023$ & $1.485 \pm 0.034$ & $1.443 \pm 0.028$ & $1.425 \pm 0.029$ & $1.421 \pm 0.031$ \\
\hline C18:0 & $76.935 \pm 1.222^{\mathrm{a}}$ & $73.433 \pm 1.011^{\mathrm{b}}$ & $72.976 \pm 1.502^{\mathrm{b}}$ & $75.852 \pm 1.223^{\mathrm{a}}$ & $74.753 \pm 1.27^{\mathrm{ab}}$ & $77.157 \pm 1.356^{\mathrm{a}}$ \\
\hline C18:1 cis-9 & $265.680 \pm 4.845^{\mathrm{a}}$ & $250.866 \pm 4.01^{\mathrm{b}}$ & $253.427 \pm 5.955$ & $259.873 \pm 4.847$ & $257.561 \pm 5.035$ & $262.231 \pm 5.375$ \\
\hline \multicolumn{7}{|l|}{ C18:1 cis- } \\
\hline 11 & $25.280 \pm 0.397^{\mathrm{a}}$ & $24.252 \pm 0.329^{b}$ & $24.010 \pm 0.488^{b}$ & $24.714 \pm 0.397^{\mathrm{a}}$ & $25.076 \pm 0.413^{\mathrm{a}}$ & $25.263 \pm 0.44^{\mathrm{a}}$ \\
\hline
\end{tabular}


C18:2 cis-9,

\begin{tabular}{|c|c|c|c|c|c|c|}
\hline cis-12 & $66.062 \pm 0.989^{b}$ & $71.472 \pm 0.819^{\mathrm{a}}$ & $74.151 \pm 1.216^{\mathrm{a}}$ & $70.766 \pm 0.989^{b}$ & $66.244 \pm 1.028^{c}$ & $63.907 \pm 1.097^{\mathrm{d}}$ \\
\hline $\mathrm{C} 18: 3 n-6$ & $0.714 \pm 0.015$ & $0.734 \pm 0.013$ & $0.755 \pm 0.019^{\mathrm{a}}$ & $0.730 \pm 0.015^{\mathrm{ab}}$ & $0.707 \pm 0.016^{\mathrm{b}}$ & $0.706 \pm 0.017^{b}$ \\
\hline $\mathrm{C} 18: 3 n-3$ & $2.243 \pm 0.057^{b}$ & $2.445 \pm 0.047^{\mathrm{a}}$ & $2.557 \pm 0.07^{\mathrm{a}}$ & $2.422 \pm 0.057^{b}$ & $2.227 \pm 0.059^{c}$ & $2.170 \pm 0.063^{c}$ \\
\hline C20:0 & $1.044 \pm 0.021^{\mathrm{a}}$ & $0.935 \pm 0.017^{b}$ & $0.943 \pm 0.026^{b}$ & $1.006 \pm 0.021^{\mathrm{a}}$ & $0.992 \pm 0.022^{\mathrm{ab}}$ & $1.016 \pm 0.023^{\mathrm{a}}$ \\
\hline \multicolumn{7}{|l|}{ C20:1 cis- } \\
\hline 11 & $4.574 \pm 0.097^{\mathrm{a}}$ & $4.123 \pm 0.08^{b}$ & $4.196 \pm 0.119$ & $4.395 \pm 0.097$ & $4.384 \pm 0.101$ & $4.420 \pm 0.108$ \\
\hline C20:2 n-6 & $2.749 \pm 0.048^{b}$ & $2.836 \pm 0.04^{\mathrm{a}}$ & $3.026 \pm 0.059^{\mathrm{a}}$ & $2.896 \pm 0.048^{b}$ & $2.686 \pm 0.05^{c}$ & $2.562 \pm 0.053^{d}$ \\
\hline$C 20: 3 n-6$ & $1.430 \pm 0.029$ & $1.584 \pm 0.024$ & $1.562 \pm 0.035^{\mathrm{a}}$ & $1.537 \pm 0.029^{\mathrm{a}}$ & $1.499 \pm 0.03^{\mathrm{a}}$ & $1.429 \pm 0.033^{b}$ \\
\hline C20:4 n-6 & $11.392 \pm 0.328^{b}$ & $12.898 \pm 0.271^{\mathrm{a}}$ & $12.785 \pm 0.403^{\mathrm{a}}$ & $12.170 \pm 0.328^{\mathrm{ab}}$ & $12.185 \pm 0.34^{\mathrm{ab}}$ & $11.440 \pm 0.363^{b}$ \\
\hline $\mathrm{C} 20: 3 n-3$ & $0.546 \pm 0.011$ & $0.560 \pm 0.009$ & $0.592 \pm 0.013^{\mathrm{a}}$ & $0.565 \pm 0.011^{b}$ & $0.532 \pm 0.011^{\mathrm{c}}$ & $0.524 \pm 0.012^{\mathrm{c}}$ \\
\hline $\mathrm{C} 20: 5 n-3$ & $0.087 \pm 0.002^{\mathrm{a}}$ & $0.077 \pm 0.002^{b}$ & $0.078 \pm 0.003^{b}$ & $0.084 \pm 0.002^{\mathrm{a}}$ & $0.083 \pm 0.002^{\mathrm{a}}$ & $0.084 \pm 0.002^{\mathrm{a}}$ \\
\hline $\mathrm{C} 22: 1$ & $0.129 \pm 0.004^{b}$ & $0.143 \pm 0.003^{\mathrm{a}}$ & $0.143 \pm 0.005^{\mathrm{a}}$ & $0.137 \pm 0.004^{\mathrm{ab}}$ & $0.135 \pm 0.004^{\mathrm{ab}}$ & $0.128 \pm 0.004^{b}$ \\
\hline $\mathrm{C} 22: 2 n-6$ & $0.519 \pm 0.024$ & $0.551 \pm 0.020$ & $0.543 \pm 0.029$ & $0.545 \pm 0.024$ & $0.541 \pm 0.025$ & $0.512 \pm 0.026$ \\
\hline $\mathrm{C} 22: 4 n-6$ & $1.847 \pm 0.040$ & $1.900 \pm 0.033$ & $2.006 \pm 0.050^{\mathrm{a}}$ & $1.896 \pm 0.040^{b}$ & $1.842 \pm 0.042^{\mathrm{bc}}$ & $1.751 \pm 0.045^{\mathrm{c}}$ \\
\hline $\mathrm{C} 22: 5 n-3$ & $0.725 \pm 0.017^{b}$ & $0.787 \pm 0.014^{\mathrm{a}}$ & $0.811 \pm 0.021^{\mathrm{a}}$ & $0.769 \pm 0.017^{b}$ & $0.746 \pm 0.018^{b}$ & $0.699 \pm 0.019^{c}$ \\
\hline $\mathrm{C} 22: 6 n-3$ & $0.189 \pm 0.006^{\mathrm{b}}$ & $0.227 \pm 0.005^{\mathrm{a}}$ & $0.237 \pm 0.007^{\mathrm{a}}$ & $0.209 \pm 0.006^{b}$ & $0.198 \pm 0.006^{\mathrm{bc}}$ & $0.189 \pm 0.007^{\mathrm{c}}$ \\
\hline
\end{tabular}




\begin{tabular}{|c|c|c|c|c|c|c|}
\hline $\mathrm{SFA}^{3}$ & $240.301 \pm 3.739^{\mathrm{a}}$ & $232.1 \pm 3.094^{b}$ & $228.804 \pm 4.596^{\mathrm{b}}$ & $237.77 \pm 3.74^{\mathrm{a}}$ & $235.438 \pm 3.886^{\mathrm{ab}}$ & $242.79 \pm 4.148^{\mathrm{a}}$ \\
\hline MUFA $^{4}$ & $315.803 \pm 5.604^{\mathrm{a}}$ & $298.997 \pm 4.638^{b}$ & $300.557 \pm 6.889$ & $308.882 \pm 5.607$ & $307.268 \pm 5.824$ & $312.894 \pm 6.217$ \\
\hline PUFA $^{5}$ & $88.356 \pm 1.194^{\mathrm{b}}$ & $95.934 \pm 0.988^{\mathrm{a}}$ & $98.97 \pm 1.468^{\mathrm{a}}$ & $94.453 \pm 1.195^{\mathrm{b}}$ & $89.355 \pm 1.241^{\mathrm{c}}$ & $85.802 \pm 1.325^{\mathrm{d}}$ \\
\hline$n-6$ PUFA $^{6}$ & $84.566 \pm 1.135^{\mathrm{b}}$ & $91.838 \pm 0.939^{\mathrm{a}}$ & $94.697 \pm 1.395^{\mathrm{a}}$ & $90.405 \pm 1.135^{\mathrm{b}}$ & $85.569 \pm 1.180^{\mathrm{c}}$ & $82.136 \pm 1.259^{\mathrm{d}}$ \\
\hline$n-3$ PUFA $^{7}$ & $3.790 \pm 0.071^{b}$ & $4.096 \pm 0.059^{\mathrm{a}}$ & $4.273 \pm 0.087^{\mathrm{a}}$ & $4.048 \pm 0.071^{\mathrm{b}}$ & $3.786 \pm 0.074^{\mathrm{c}}$ & $3.666 \pm 0.079^{c}$ \\
\hline$n-6 / n-3$ ratio & $22.860 \pm 0.283$ & $22.904 \pm 0.234$ & $22.586 \pm 0.348$ & $22.837 \pm 0.283$ & $23.218 \pm 0.294$ & $22.886 \pm 0.314$ \\
\hline
\end{tabular}

${ }^{\mathrm{T}}$ Fatty acids were expressed as mg/g of Semimembranosus muscle intramuscular fat, while intramuscular fat (IMF) was expressed as \%.

${ }^{2}$ Intramuscular fat content measured in Semimembranosus muscle by means of a XT15 Ankom apparatus according to Official procedure AOCS Am 5-04 (expressed as \%).

${ }^{3}$ Saturated fatty acids.

${ }^{4}$ Monounsaturated fatty acids.

${ }^{5}$ Polyunsaturated fatty acids.

${ }^{6}$ Omega-6 polyunsaturated fatty acids.

${ }^{7}$ Omega-3 polyunsaturated fatty acids. 
Table 3. Genetic variance $\left(\sigma_{\mathrm{a}}^{2}\right)$, litter variance $\left(\sigma_{\mathrm{f}}^{2}\right)$, error variance $\left(\sigma_{\mathrm{e}}^{2}\right)$, total variance $\left(\sigma_{\mathrm{t}}^{2}\right)$, heritability $\left(\mathrm{h}^{2}\right)$ and heritability standard error $(\mathrm{SE})$ for Semimembranosus muscle fatty acid composition.

\begin{tabular}{lcccccc}
\hline Traits $^{1}$ & $\sigma_{\mathrm{a}}{ }^{2}$ & $\sigma_{\mathrm{f}}{ }^{2}$ & $\sigma_{\mathrm{e}}{ }^{2}$ & $\sigma_{\mathrm{t}}{ }^{2}$ & $\mathrm{~h}^{2}$ & $\mathrm{SE}$ \\
\hline $\mathrm{C} 10: 0$ & $6.480 \mathrm{E}+02$ & $2.422 \mathrm{E}+02$ & $2.775 \mathrm{E}+03$ & $3.666 \mathrm{E}+03$ & 0.177 & 0.004 \\
$\mathrm{C} 12: 0$ & $2.328 \mathrm{E}+03$ & $4.620 \mathrm{E}+02$ & $7.745 \mathrm{E}+03$ & $1.053 \mathrm{E}+04$ & 0.221 & 0.002 \\
$\mathrm{C} 14: 0$ & $6.964 \mathrm{E}+05$ & $1.147 \mathrm{E}+05$ & $2.186 \mathrm{E}+06$ & $2.997 \mathrm{E}+06$ & 0.232 & 0.001 \\
$\mathrm{C} 16: 0$ & $1.936 \mathrm{E}+08$ & $3.071 \mathrm{E}+07$ & $6.109 \mathrm{E}+08$ & $8.352 \mathrm{E}+08$ & 0.232 & 0.001 \\
$\mathrm{C} 16: 1$ cis-9 & $5.146 \mathrm{E}+06$ & $8.736 \mathrm{E}+05$ & $1.595 \mathrm{E}+07$ & $2.197 \mathrm{E}+07$ & 0.234 & 0.001 \\
$\mathrm{C} 17: 0$ & $4.343 \mathrm{E}+03$ & $5.081 \mathrm{E}+02$ & $1.520 \mathrm{E}+04$ & $2.005 \mathrm{E}+04$ & 0.217 & 0.002 \\
$\mathrm{C} 17: 1$ cis-9 & $1.090 \mathrm{E}+04$ & $1.861 \mathrm{E}+03$ & $3.836 \mathrm{E}+04$ & $5.112 \mathrm{E}+04$ & 0.213 & 0.002 \\
$\mathrm{C} 18: 0$ & $6.799 \mathrm{E}+07$ & $8.911 \mathrm{E}+06$ & $2.189 \mathrm{E}+08$ & $2.958 \mathrm{E}+08$ & 0.230 & 0.001 \\
$\mathrm{C} 18: 1$ cis-9 & $1.637 \mathrm{E}+09$ & $2.211 \mathrm{E}+08$ & $5.322 \mathrm{E}+09$ & $7.181 \mathrm{E}+09$ & 0.228 & 0.001 \\
$\mathrm{C} 18: 1$ cis-11 & $9.631 \mathrm{E}+06$ & $1.425 \mathrm{E}+06$ & $3.041 \mathrm{E}+07$ & $4.146 \mathrm{E}+07$ & 0.232 & 0.001 \\
$\mathrm{C} 18: 2$ cis-9, cis-12 & $3.631 \mathrm{E}+07$ & $3.799 \mathrm{E}+06$ & $1.256 \mathrm{E}+08$ & $1.657 \mathrm{E}+08$ & 0.219 & 0.001 \\
$\mathrm{C} 18: 3$ n-6 & $5.453 \mathrm{E}+03$ & $6.439 \mathrm{E}+02$ & $1.967 \mathrm{E}+04$ & $2.576 \mathrm{E}+04$ & 0.212 & 0.001 \\
C18:3 n-3 & $2.500 \mathrm{E}+05$ & $2.283 \mathrm{E}+04$ & $8.461 \mathrm{E}+05$ & $1.119 \mathrm{E}+06$ & 0.223 & 0.001 \\
C20:0 & $2.021 \mathrm{E}+04$ & $2.809 \mathrm{E}+03$ & $6.615 \mathrm{E}+04$ & $8.917 \mathrm{E}+04$ & 0.227 & 0.001
\end{tabular}




$\begin{array}{lllllll}\mathrm{C} 20: 1 \text { cis-11 } & 7.248 \mathrm{E}+05 & 1.006 \mathrm{E}+05 & 2.325 \mathrm{E}+06 & 3.150 \mathrm{E}+06 & 0.230 & 0.001 \\ \mathrm{C} 20: 2 n-6 & 1.880 \mathrm{E}+05 & 1.822 \mathrm{E}+04 & 6.246 \mathrm{E}+05 & 8.309 \mathrm{E}+05 & 0.226 & 0.001 \\ \mathrm{C} 20: 3 n-6 & 2.395 \mathrm{E}+04 & 5.956 \mathrm{E}+03 & 7.423 \mathrm{E}+04 & 1.041 \mathrm{E}+05 & 0.230 & 0.001 \\ \mathrm{C} 20: 4 n-6 & 6.354 \mathrm{E}+06 & 1.249 \mathrm{E}+06 & 1.977 \mathrm{E}+07 & 2.737 \mathrm{E}+07 & 0.232 & 0.001 \\ \mathrm{C} 20: 3 n-3 & 6.176 \mathrm{E}+03 & 8.584 \mathrm{E}+02 & 1.939 \mathrm{E}+04 & 2.642 \mathrm{E}+04 & 0.234 & 0.001 \\ \mathrm{C} 20: 5 n-3 & 8.593 \mathrm{E}+01 & 1.297 \mathrm{E}+01 & 3.072 \mathrm{E}+02 & 4.061 \mathrm{E}+02 & 0.212 & 0.001 \\ \mathrm{C} 22: 1 & 4.743 \mathrm{E}+02 & 1.080 \mathrm{E}+02 & 1.436 \mathrm{E}+03 & 2.019 \mathrm{E}+03 & 0.235 & 0.001 \\ \mathrm{C} 22: 2 n-6 & 4.599 \mathrm{E}+04 & 7.655 \mathrm{E}+03 & 1.452 \mathrm{E}+05 & 1.988 \mathrm{E}+05 & 0.231 & 0.001 \\ \mathrm{C} 22: 4 n-6 & 9.938 \mathrm{E}+04 & 1.855 \mathrm{E}+04 & 3.057 \mathrm{E}+05 & 4.236 \mathrm{E}+05 & 0.235 & 0.001 \\ \mathrm{C} 22: 5 n-3 & 1.655 \mathrm{E}+04 & 3.182 \mathrm{E}+03 & 5.073 \mathrm{E}+04 & 7.046 \mathrm{E}+04 & 0.235 & 0.001 \\ \mathrm{C} 22: 6 n-3 & 1.386 \mathrm{E}+03 & 3.086 \mathrm{E}+02 & 4.147 \mathrm{E}+03 & 5.842 \mathrm{E}+03 & 0.237 & 0.001\end{array}$

${ }^{1}$ Fatty acids were expressed as mg/g of Semimembranosus muscle intramuscular fat. 
Table 4. Genetic variance $\left(\sigma_{\mathrm{a}}^{2}\right)$, litter variance $\left(\sigma_{\mathrm{f}}^{2}\right)$, error variance $\left(\sigma_{\mathrm{e}}{ }^{2}\right)$, total variance $\left(\sigma_{\mathrm{t}}^{2}\right)$, heritability $\left(\mathrm{h}^{2}\right)$ and heritability standard error $(\mathrm{SE})$ for the fatty acid classes in Semimembranosus muscle.

\begin{tabular}{|c|c|c|c|c|c|c|}
\hline Traits $^{1}$ & $\sigma_{a}^{2}$ & $\sigma_{\mathrm{f}}^{2}$ & $\sigma_{\mathrm{e}}^{2}$ & $\sigma_{t}^{2}$ & $\mathrm{~h}^{2}$ & $\mathrm{SE}$ \\
\hline $\mathrm{IMF}^{2}$ & $2.562 \mathrm{E}+04$ & $1.716 \mathrm{E}+04$ & $1.488 \mathrm{E}+05$ & $1.916 \mathrm{E}+05$ & 0.134 & 0.002 \\
\hline Total lipids & $3.681 \mathrm{E}+08$ & $1.952 \mathrm{E}+08$ & $1.783 \mathrm{E}+09$ & $2.347 \mathrm{E}+09$ & 0.157 & 0.002 \\
\hline $\mathrm{SFA}^{3}$ & $9.983 \mathrm{E}+08$ & $1.353 \mathrm{E}+08$ & $3.296 \mathrm{E}+09$ & $4.430 \mathrm{E}+09$ & 0.225 & 0.001 \\
\hline MUFA $^{4}$ & $3.274 \mathrm{E}+09$ & $4.446 \mathrm{E}+08$ & $1.079 \mathrm{E}+10$ & $1.451 \mathrm{E}+10$ & 0.226 & 0.001 \\
\hline PUFA $^{5}$ & $1.466 \mathrm{E}+08$ & $1.697 \mathrm{E}+07$ & $4.837 \mathrm{E}+08$ & $6.473 \mathrm{E}+08$ & 0.226 & 0.001 \\
\hline$n-6$ PUFA $^{6}$ & $1.937 \mathrm{E}+07$ & $6.523 \mathrm{E}+06$ & $6.698 \mathrm{E}+07$ & $9.288 \mathrm{E}+07$ & 0.209 & 0.002 \\
\hline$n-3$ PUFA $^{7}$ & $2.876 \mathrm{E}+05$ & $3.543 \mathrm{E}+04$ & $9.743 \mathrm{E}+05$ & $1.297 \mathrm{E}+06$ & 0.222 & 0.002 \\
\hline$n-6 / n-3$ ratio & $3.896 \mathrm{E}+06$ & $5.409 \mathrm{E}+05$ & $1.266 \mathrm{E}+07$ & $1.709 \mathrm{E}+07$ & 0.228 & 0.001 \\
\hline
\end{tabular}

${ }^{1}$ Fatty acids were expressed as mg/g of Semimembranosus muscle intramuscular fat, while intramuscular fat (IMF) was expressed as \%.

${ }^{2}$ Intramuscular fat content measured in Semimembranosus muscle by means of a XT15 Ankom apparatus according to Official procedure AOCS Am 5-04 (expressed as \%).

${ }^{3}$ Saturated fatty acids.

${ }^{4}$ Monounsaturated fatty acids.

${ }^{5}$ Polyunsaturated fatty acids. 
${ }^{6}$ Omega-6 polyunsaturated fatty acids.

${ }^{7}$ Omega-3 polyunsaturated fatty acids. 
Table 5. Genetic correlation coefficients $\left(\mathrm{r}_{\mathrm{g}}\right) \pm$ the relative standard errors between Semimembranosus muscle fatty acid composition and carcass traits.

\begin{tabular}{|c|c|c|c|c|c|c|}
\hline & Hot carcass & $\mathrm{BFT}^{2}$ & $\operatorname{Lean}^{3}$ & BFT FOM $^{4}$ & Loin thickness $^{5}$ & $\mathrm{IMF}^{6}$ \\
\hline Traits $^{1}$ & weight $(\mathrm{kg})$ & $(\mathrm{mm})$ & $(\%)$ & $(\mathrm{mm})$ & $(\mathrm{mm})$ & $(\%)$ \\
\hline C10:0 & $-0.062 \pm 0.012$ & $0.076 \pm 0.013 *$ & $-0.282 \pm 0.012 * * *$ & $0.367 \pm 0.011 * * *$ & $-0.319 \pm 0.011$ & $0.768 \pm 0.009 * * *$ \\
\hline C12:0 & $-0.031 \pm 0.005$ & $0.030 \pm 0.005$ & $0.020 \pm 0.005$ & $0.001 \pm 0.005$ & $0.009 \pm 0.005$ & $0.301 \pm 0.005 * * *$ \\
\hline C14:0 & $-0.037 \pm 0.003$ & $0.039 \pm 0.004$ & $-0.051 \pm 0.004$ & $0.067 \pm 0.003$ & $-0.043 \pm 0.004$ & $0.241 \pm 0.003 * * *$ \\
\hline C16:0 & $-0.028 \pm 0.003$ & $0.031 \pm 0.003$ & $-0.056 \pm 0.003$ & $0.079 \pm 0.003^{*}$ & $-0.064 \pm 0.003$ & $0.206 \pm 0.003 * * *$ \\
\hline C16:1 cis-9 & $-0.038 \pm 0.003$ & $0.042 \pm 0.003$ & $-0.089 \pm 0.003 *$ & $0.101 \pm 0.003 * *$ & $-0.061 \pm 0.003$ & $0.176 \pm 0.003 * * *$ \\
\hline C17:0 & $0.099 \pm 0.004 * *$ & $-0.107 \pm 0.005^{* *}$ & $0.174 \pm 0.005 * * *$ & $-0.169 \pm 0.004 * * *$ & $0.088 \pm 0.005^{*}$ & $0.023 \pm 0.006$ \\
\hline $\mathrm{C} 17: 1$ cis -9 & $0.032 \pm 0.005$ & $-0.037 \pm 0.005$ & $0.107 \pm 0.005^{* *}$ & $-0.119 \pm 0.005 * * *$ & $0.101 \pm 0.005^{* *}$ & $-0.042 \pm 0.005$ \\
\hline C18:0 & $-0.022 \pm 0.002$ & $0.024 \pm 0.003$ & $-0.045 \pm 0.003$ & $0.078 \pm 0.003^{*}$ & $-0.084 \pm 0.003^{*}$ & $0.167 \pm 0.003 * * *$ \\
\hline C18:1 cis -9 & $-0.015 \pm 0.002$ & $0.016 \pm 0.002$ & $-0.014 \pm 0.002$ & $0.022 \pm 0.002$ & $-0.011 \pm 0.002$ & $0.117 \pm 0.002 * * *$ \\
\hline \multicolumn{7}{|l|}{ C18:1 cis- } \\
\hline 11 & $-0.023 \pm 0.002$ & $0.025 \pm 0.002$ & $-0.038 \pm 0.002$ & $0.049 \pm 0.002$ & $-0.028 \pm 0.002$ & $0.123 \pm 0.002 * * *$ \\
\hline \multicolumn{7}{|l|}{ C18:2 cis-9, } \\
\hline$c i s-12$ & $0.078 \pm 0.003^{* *}$ & $-0.088 \pm 0.005^{*}$ & $0.217 \pm 0.003 * * *$ & $-0.237 \pm 0.003 * * *$ & $0.171 \pm 0.003 * * *$ & $-0.067 \pm 0.005$ \\
\hline
\end{tabular}




\begin{tabular}{|c|c|c|c|c|c|c|}
\hline C18:3n-6 & $0.032 \pm 0.004$ & $-0.037 \pm 0.004$ & $0.099 \pm 0.004 * *$ & $-0.127 \pm 0.004 * * *$ & $0.11 \pm 0.004 * *$ & $-0.073 \pm 0.004^{*}$ \\
\hline C18:3n-3 & $0.030 \pm 0.002$ & $-0.035 \pm 0.003$ & $0.109 \pm 0.002 * *$ & $-0.122 \pm 0.002 * * *$ & $0.096 \pm 0.002 * *$ & $0.001 \pm 0.003$ \\
\hline C20:0 & $-0.009 \pm 0.003$ & $0.01 \pm 0.003$ & $-0.029 \pm 0.003$ & $0.057 \pm 0.003$ & $-0.068 \pm 0.003$ & $0.084 \pm 0.003^{*}$ \\
\hline \multicolumn{7}{|l|}{ C20:1 cis- } \\
\hline 11 & $-0.024 \pm 0.002$ & $0.025 \pm 0.002$ & $-0.018 \pm 0.002$ & $0.028 \pm 0.002$ & $-0.014 \pm 0.002$ & $0.108 \pm 0.002 * *$ \\
\hline $\mathrm{C} 20: 2 n-6$ & $0.048 \pm 0.002$ & $-0.054 \pm 0.003$ & $0.139 \pm 0.002 * * *$ & $-0.149 \pm 0.002 * * *$ & $0.106 \pm 0.002 * *$ & $-0.025 \pm 0.004$ \\
\hline $\mathrm{C} 20: 3 n-6$ & $0.024 \pm 0.004$ & $-0.029 \pm 0.004$ & $0.098 \pm 0.004 * *$ & $-0.099 \pm 0.004 * *$ & $0.067 \pm 0.004$ & $-0.133 \pm 0.004 * * *$ \\
\hline $\mathrm{C} 20: 4 n-6$ & $0.018 \pm 0.002$ & $-0.021 \pm 0.003$ & $0.054 \pm 0.002$ & $-0.062 \pm 0.002$ & $0.045 \pm 0.002$ & $-0.115 \pm 0.002 * *$ \\
\hline $\mathrm{C} 20: 3 n-3$ & $0.019 \pm 0.002$ & $-0.025 \pm 0.003$ & $0.108 \pm 0.003 * *$ & $-0.137 \pm 0.002 * * *$ & $0.132 \pm 0.002 * * *$ & $-0.010 \pm 0.004$ \\
\hline $\mathrm{C} 20: 5 n-3$ & $0.001 \pm 0.004$ & $0.001 \pm 0.004$ & $-0.037 \pm 0.004$ & $0.021 \pm 0.004$ & $-0.008 \pm 0.004$ & $0.067 \pm 0.004$ \\
\hline C22:1 & $0.011 \pm 0.003$ & $-0.015 \pm 0.003$ & $0.074 \pm 0.003 *$ & $-0.088 \pm 0.003 *$ & $0.075 \pm 0.003 *$ & $-0.089 \pm 0.003 *$ \\
\hline $\mathrm{C} 22: 2 n-6$ & $0.022 \pm 0.002$ & $-0.023 \pm 0.002$ & $0.026 \pm 0.002$ & $-0.014 \pm 0.002$ & $-0.017 \pm 0.002$ & $-0.078 \pm 0.002^{*}$ \\
\hline $\mathrm{C} 22: 4 n-6$ & $0.032 \pm 0.002$ & $-0.037 \pm 0.003$ & $0.090 \pm 0.002 *$ & $-0.094 \pm 0.002 * *$ & $0.066 \pm 0.002$ & $-0.118 \pm 0.003 * * *$ \\
\hline $\mathrm{C} 22: 5 n-3$ & $0.033 \pm 0.003$ & $-0.037 \pm 0.003$ & $0.092 \pm 0.003 * *$ & $-0.102 \pm 0.003 * *$ & $0.078 \pm 0.003 *$ & $-0.075 \pm 0.003^{*}$ \\
\hline $\mathrm{C} 22: 6 n-3$ & $0.058 \pm 0.003$ & $-0.065 \pm 0.004$ & $0.132 \pm 0.003 * * *$ & $-0.178 \pm 0.003 * * *$ & $0.146 \pm 0.003 * * *$ & $-0.098 \pm 0.004 * *$ \\
\hline
\end{tabular}

$* P$-value $\leq 0.05 ; * * P$-value $\leq 0.01 ; * * * P$-value $\leq 0.001$.

${ }^{1}$ Fatty acids were expressed as mg/g of Semimembranosus muscle intramuscular fat. 
${ }^{2}$ Backfat thickness manually measured with a calibre at the level of Gluteus medius muscle.

${ }^{3}$ Percentage of carcass lean meat content estimated using Fat-O-Meat'er (FOM) instrument.

${ }^{4}$ Backfat thickness (including rind) measured with Fat-O-Meat'er (FOM) instrument on the back between the third and fourth last ribs at $8 \mathrm{~cm}$ off the carcass midline.

${ }^{5}$ Loin thickness measured with Fat-O-Meat'er (FOM) instrument on the back between the third and fourth last ribs at $8 \mathrm{~cm}$ off the carcass midline.

${ }^{6}$ Intramuscular fat content measured in Semimembranosus muscle by means of a XT15 Ankom apparatus according to Official procedure AOCS Am 5-04. 
Table 6. Genetic correlation coefficients $\left(\mathrm{r}_{\mathrm{g}}\right) \pm$ the relative standard errors between the fatty acid classes in Semimembranosus muscle and carcass traits.

\begin{tabular}{|c|c|c|c|c|c|c|}
\hline Traits $^{1}$ & $\begin{array}{l}\text { Hot carcass } \\
\text { weight }(\mathrm{kg})\end{array}$ & $\begin{array}{l}\mathrm{BFT}^{2} \\
(\mathrm{~mm})\end{array}$ & $\begin{array}{c}\text { Lean }^{3} \\
(\%)\end{array}$ & $\begin{array}{c}\text { BFT FOM }^{4} \\
(\mathrm{~mm})\end{array}$ & $\begin{array}{c}\text { Loin thickness }^{5} \\
(\mathrm{~mm})\end{array}$ & $\begin{array}{c}\mathrm{IMF}^{6} \\
(\%)\end{array}$ \\
\hline Total lipids & $-0.048 \pm 0.008$ & $0.048 \pm 0.008$ & $-0.018 \pm 0.008$ & $0.093 \pm 0.008^{* *}$ & $-0.089 \pm 0.008 * *$ & $0.731 \pm 0.006 * * *$ \\
\hline$n-6$ PUFA $^{7}$ & $0.203 \pm 0.005^{* * *}$ & $-0.225 \pm 0.008 * * *$ & $0.563 \pm 0.005 * * *$ & $-0.603 \pm 0.004 * * *$ & $0.438 \pm 0.005^{* * *}$ & $-0.267 \pm 0.009 * * *$ \\
\hline$n-3$ PUFA $^{8}$ & $0.07 \pm 0.002^{*}$ & $-0.079 \pm 0.004^{*}$ & $0.236 \pm 0.003 * * *$ & $-0.265 \pm 0.002 * * *$ & $0.216 \pm 0.003 * * *$ & $-0.035 \pm 0.004$ \\
\hline$n-6 / n-3$ ratio & $0.014 \pm 0.003$ & $-0.012 \pm 0.003$ & $-0.048 \pm 0.003$ & $0.076 \pm 0.003^{*}$ & $-0.107 \pm 0.003 * *$ & $-0.134 \pm 0.003^{* * *}$ \\
\hline $\mathrm{SFA}^{9}$ & $-0.025 \pm 0.002$ & $0.027 \pm 0.002$ & $-0.054 \pm 0.002$ & $0.086 \pm 0.002 *$ & $-0.084 \pm 0.002 *$ & $0.214 \pm 0.002 * * *$ \\
\hline MUFA $^{10}$ & $-0.017 \pm 0.002$ & $0.018 \pm 0.002$ & $-0.021 \pm 0.002$ & $0.033 \pm 0.002$ & $-0.021 \pm 0.002$ & $0.145 \pm 0.002 * * *$ \\
\hline PUFA $^{11}$ & $0.077 \pm 0.002 *$ & $-0.085 \pm 0.003^{*}$ & $0.215 \pm 0.002 * * *$ & $-0.231 \pm 0.002 * * *$ & $0.169 \pm 0.002 * * *$ & $-0.099 \pm 0.003 * *$ \\
\hline
\end{tabular}

$* P$-value $\leq 0.05 ; * * P$-value $\leq 0.01 ; * * *$-value $\leq 0.001$.

${ }^{1}$ Fatty acid classes were expressed as mg/g of Semimembranosus muscle intramuscular fat.

${ }^{2}$ Backfat thickness manually measured with a calibre at the level of Gluteus medius muscle.

${ }^{3}$ Percentage of carcass lean meat content estimated using Fat-O-Meat'er (FOM) instrument. 
${ }^{4}$ Backfat thickness (including rind) measured with Fat-O-Meat'er (FOM) instrument on the back between the third and fourth last ribs at $8 \mathrm{~cm}$ off the carcass midline.

${ }^{5}$ Loin thickness measured with Fat-O-Meat'er (FOM) instrument on the back between the third and fourth last ribs at $8 \mathrm{~cm}$ off the carcass midline.

${ }^{6}$ Intramuscular fat content measured in Semimembranosus muscle by means of a XT15 Ankom apparatus according to Official procedure AOCS Am 5-04.

${ }^{7}$ Omega- 6 polyunsaturated fatty acids.

${ }^{8}$ Omega-3 polyunsaturated fatty acids.

${ }^{9}$ Saturated fatty acids.

${ }^{10}$ Monounsaturated fatty acids.

${ }^{11}$ Polyunsaturated fatty acids. 
Table 7. Genetic correlations (above diagonal), standard errors (below diagonal) and heritabilities (diagonal, in bold) for the fatty acid classes in Semimembranosus muscle.

\begin{tabular}{lccccccc}
\hline Traits & Total lipids & $n-6$ PUFA $^{2}$ & $n-3$ PUFA $^{3}$ & $n-6 / n-3$ & SFA $^{4}$ & MUFA $^{5}$ & PUFA $^{6}$ \\
\hline Total lipids & $\mathbf{0 . 1 5 7}$ & $0.313 * * *$ & $0.392^{* * *}$ & $-0.554 * * *$ & $0.635 * * *$ & $0.515^{* * *}$ & $0.131^{* * *}$ \\
$n-6$ PUFA $^{2}$ & 0.009 & $\mathbf{0 . 2 0 9}$ & $0.716^{* * *}$ & $-0.517 * * *$ & $0.398 * * *$ & $0.367 * * *$ & $0.477 * * *$ \\
$n-3$ PUFA $^{3}$ & 0.005 & 0.004 & $\mathbf{0 . 2 2 2}$ & $-0.691 * * *$ & $0.583 * * *$ & $0.471 * * *$ & $0.812^{* * *}$ \\
$n-6 / n-3$ ratio & 0.004 & 0.003 & 0.002 & $\mathbf{0 . 2 2 8}$ & $-0.878^{* * * *}$ & $-0.722^{* * *}$ & $-0.753 * * *$ \\
SFA $^{4}$ & 0.004 & 0.004 & 0.002 & 0.002 & $\mathbf{0 . 2 2 5}$ & $0.883 * * *$ & $0.591 * * *$ \\
MUFA $^{5}$ & 0.003 & 0.003 & 0.002 & 0.002 & 0.001 & $\mathbf{0 . 2 2 6}$ & $0.562 * * *$ \\
PUFA $^{6}$ & 0.004 & 0.003 & 0.002 & 0.002 & 0.002 & 0.002 & $\mathbf{0 . 2 2 6}$
\end{tabular}

*** $P$-value $\leq 0.0 \overline{01}$

${ }^{1}$ Fatty acid classes were expressed as mg/g of Semimembranosus muscle intramuscular fat.

${ }^{2}$ Omega- 6 polyunsaturated fatty acids.

${ }^{3}$ Omega-3 polyunsaturated fatty acids.

${ }^{4}$ Saturated fatty acids.

${ }^{5}$ Monounsaturated fatty acids. 
${ }^{6}$ Polyunsaturated fatty acids 


\section{Figure captions}

Figure 1. Histogram showing the estimates of the genomic and pedigree-based heritabilities $\left(\mathrm{h}^{2}\right)$ for Semimembranosus muscle fatty acid composition.

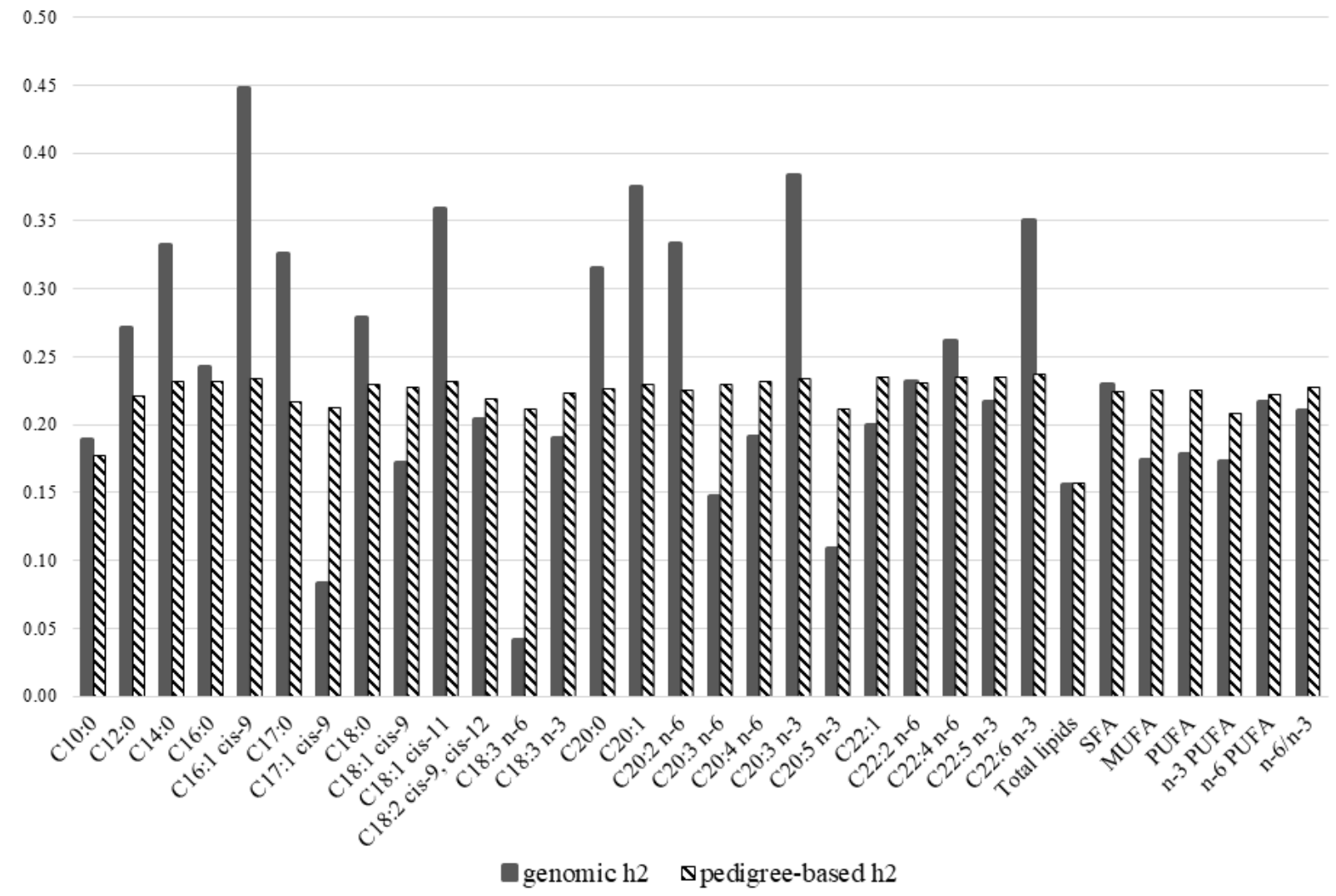




\section{Supplementary Material}

Supplementary Table S1. List of the analysed fatty acids and fatty acid categories with shorthand notation, IUPAC and common nomenclature.

Supplementary Table S2. Estimates of the genomic and pedigree-based heritabilities for Semimembranosus muscle fatty acid composition.

Supplementary Table S3. Genetic correlations (above diagonal), standard errors (below diagonal) and heritabilities (diagonal, in bold) for Semimembranosus muscle fatty acid composition. 
Supplementary Table S1. List of the analysed fatty acids and fatty acid categories with shorthand notation, IUPAC and common nomenclature.

\begin{tabular}{|c|c|c|}
\hline Shorthand notation & IUPAC nomenclature & Common nomenclature \\
\hline C10:0 & Decanoic acid & Capric acid \\
\hline C12:0 & Dodecanoic acid & Lauric acid \\
\hline C14:0 & Tetradecanoic acid & Myristic acid \\
\hline C16:0 & Hexadecanoic acid & Palmitic acid \\
\hline C16:1 cis-9 & (9Z)-Hexadec-9-enoic acid & Palmitoleic acid \\
\hline C17:0 & Heptadecanoic acid & Margaric acid \\
\hline C17:1 cis-9 & Heptadecenoic acid & Heptadecenoic acid \\
\hline C18:0 & Octadecanoic acid & Stearic acid \\
\hline C18:1 cis-9 & (9Z)-Octadec-9-enoic acid & Oleic acid \\
\hline C18:1 cis-11 & (E)-Octadec-11-enoic acid & Vaccenic acid \\
\hline $\mathrm{C} 18: 2$ cis -9, cis -12 & $\begin{array}{c}(9 \mathrm{Z}, 12 \mathrm{Z})-9,12- \\
\text { Octadecadienoic acid }\end{array}$ & Linoleic acid \\
\hline $\mathrm{C} 18: 3 n-6$ & $\begin{array}{c}\text { (6Z,9Z,12Z)-octadeca- } \\
6,9,12 \text {-trienoic acid }\end{array}$ & $\gamma$-Linolenic acid \\
\hline $\mathrm{C} 18: 3 n-3$ & $\begin{array}{l}(9 Z, 12 Z, 15 Z)-9,12,15- \\
\text { Octadecatrienoic acid }\end{array}$ & $\alpha$-Linolenic acid \\
\hline С20:0 & Eicosanoic acid & Arachidic acid \\
\hline C20:1 & (9Z)-9-Icosenoic acid & Gadoleic acid \\
\hline$C 20: 2 n-6$ & $\begin{array}{c}(11 Z, 14 Z)-\text { Icosa-11,14- } \\
\text { dienoic acid }\end{array}$ & Eicosadienoic acid \\
\hline $\mathrm{C} 20: 3 n-6$ & $\begin{array}{l}\text { (8Z,11Z,14Z)-Icosa- } \\
\text { 8,11,14-trienoic acid }\end{array}$ & $\begin{array}{l}\text { Dihomo-gamma-linolenic } \\
\text { acid }\end{array}$ \\
\hline $\mathrm{C} 20: 4 n-6$ & $\begin{array}{l}(5 Z, 8 Z, 11 Z, 14 Z) \text {-Icosa- } \\
5,8,11,14 \text {-tetraenoic acid }\end{array}$ & Arachidonic acid \\
\hline $\mathrm{C} 20: 3 n-3$ & $\begin{array}{l}(\mathrm{Z}, \mathrm{Z}, \mathrm{Z})-11,14,17- \\
\text { Eicosatrienoic acid }\end{array}$ & Eicosatrienoic acid (ETE) \\
\hline $\mathrm{C} 20: 5 n-3$ & $\begin{array}{c}(5 \mathrm{Z}, 8 \mathrm{Z}, 11 \mathrm{Z}, 14 \mathrm{Z}, 17 \mathrm{Z})- \\
\text { icosa-5,8,11,14,17- } \\
\text { pentaenoic acid }\end{array}$ & $\begin{array}{l}\text { Eicosapentaenoic acid } \\
\text { (EPA) }\end{array}$ \\
\hline C22:1 & (Z)-Docos-13-enoic acid & Erucic acid \\
\hline $\mathrm{C} 22: 2 n-6$ & $\begin{array}{c}(13 Z, 16 Z)-D o c o s a-13,16- \\
\text { dienoic acid }\end{array}$ & Docosadienoic acid \\
\hline
\end{tabular}


C22:4 n-6

$\mathrm{C} 22: 5 n-3$

$\mathrm{C} 22: 6 n-3$
(7Z,10Z,13Z,16Z)-

Docosa-7,10,13,16-

tetraenoic acid

(7Z,10Z,13Z,16Z,19Z)docosa-7,10,13,16,19-

pentaenoic acid

(4Z,7Z,10Z,13Z,16Z,19Z)-

Docosa-4,7,10,13,16,19-

hexaenoic acid
Adrenic acid

Docosapentaenoic acid

(DPA)

Docosahexaenoic acid (DHA) 
Supplementary Table S2. Estimates of the genomic and pedigree-based heritabilities for Semimembranosus muscle fatty acid composition.

\begin{tabular}{|c|c|c|}
\hline Traits $^{1}$ & Genomic heritability & Pedigree-based heritability \\
\hline C10:0 & 0.189 & 0.177 \\
\hline C12:0 & 0.271 & 0.221 \\
\hline C14:0 & 0.332 & 0.232 \\
\hline C16:0 & 0.242 & 0.232 \\
\hline C16:1 cis-9 & 0.448 & 0.234 \\
\hline $\mathrm{C} 17: 0$ & 0.326 & 0.217 \\
\hline C17:1 cis-9 & 0.083 & 0.213 \\
\hline C18:0 & 0.279 & 0.230 \\
\hline C18:1 cis-9 & 0.172 & 0.228 \\
\hline C18:1 cis-11 & 0.359 & 0.232 \\
\hline $\mathrm{C} 18: 2$ cis- 9, cis-12 & 0.204 & 0.219 \\
\hline $\mathrm{C} 18: 3 n-6$ & 0.041 & 0.212 \\
\hline $\mathrm{C} 18: 3 n-3$ & 0.190 & 0.223 \\
\hline C20:0 & 0.315 & 0.227 \\
\hline C20:1 & 0.375 & 0.230 \\
\hline $\mathrm{C} 20: 2 n-6$ & 0.333 & 0.226 \\
\hline $\mathrm{C} 20: 3 n-6$ & 0.147 & 0.230 \\
\hline $\mathrm{C} 20: 4 n-6$ & 0.191 & 0.232 \\
\hline $\mathrm{C} 20: 3 n-3$ & 0.384 & 0.234 \\
\hline $\mathrm{C} 20: 5 n-3$ & 0.109 & 0.212 \\
\hline C22:1 & 0.200 & 0.235 \\
\hline $\mathrm{C} 22: 2 n-6$ & 0.232 & 0.231 \\
\hline
\end{tabular}




\begin{tabular}{|c|c|c|}
\hline $\mathrm{C} 22: 4 n-6$ & 0.262 & 0.235 \\
\hline $\mathrm{C} 22: 5 n-3$ & 0.217 & 0.235 \\
\hline $\mathrm{C} 22: 6 n-3$ & 0.350 & 0.237 \\
\hline Total lipids & 0.156 & 0.157 \\
\hline $\mathrm{SFA}^{2}$ & 0.230 & 0.225 \\
\hline $\mathrm{MUFA}^{3}$ & 0.174 & 0.226 \\
\hline PUFA $^{4}$ & 0.178 & 0.226 \\
\hline$n-3$ PUFA $^{5}$ & 0.173 & 0.209 \\
\hline$n-6$ PUFA $^{6}$ & 0.217 & 0.222 \\
\hline$n-6 / n-3$ ratio & 0.210 & 0.228 \\
\hline
\end{tabular}

${ }^{1}$ Fatty acids and fatty acid classes were measured as mg/g of Semimembranosus muscle intramuscular fat.

${ }^{2}$ Saturated fatty acids.

${ }^{3}$ Monounsaturated fatty acids.

${ }^{4}$ Polyunsaturated fatty acids.

${ }^{5}$ Omega-3 polyunsaturated fatty acids.

${ }^{6}$ Omega-6 polyunsaturated fatty acids. 